\title{
Determinants of participation in voluntary work: a systematic review and meta-analysis of longitudinal cohort studies
}

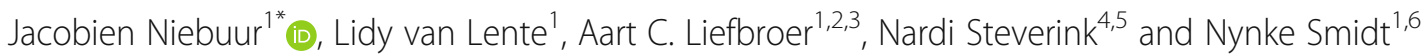

\begin{abstract}
Background: Participation in voluntary work may be associated with individual and societal benefits. Because of these benefits and as a result of challenges faced by governments related to population ageing, voluntary work becomes more important for society, and policy measures are aimed at increasing participation rates. In order to effectively identify potential volunteers, insight in the determinants of volunteering is needed. Therefore, we conducted a systematic review including meta-analyses.

Methods: A systematic search in MEDLINE, PsycINFO, SocINDEX, Business Source Premier, and EconLit was performed on August 12th 2015. We included longitudinal cohort studies conducted in developed countries that quantified factors associated with volunteering among samples from the general adult population. Two reviewers independently selected eligible studies, extracted the data and assessed the risk of bias of the included studies using the QUIPS tool. Estimates reported in the papers were transformed into Odds Ratios and $95 \%$ Confidence Intervals. For each determinant, random-effects meta-analyses were used to generate summary estimates.

Results: We found that socioeconomic status, being married, social network size, church attendance and previous volunteer experiences are positively associated with volunteering. Age, functional limitations and transitions into parenthood were found to be inversely related to volunteering.

Conclusions: Important key factors have been identified as well as gaps in the current literature. Future research should be directed towards deepening the knowledge on the associations between the factors age, education, income, employment and participation in voluntary work. Moreover, major life course transitions should be studied in relation to volunteering.
\end{abstract}

Keywords: Social participation, Volunteers, Factors, Determinants, Participation, General population, Unpaid work, Review, Meta-analysis

\footnotetext{
* Correspondence: j.niebuur@umcg.nl

${ }^{1}$ Department of Epidemiology, University of Groningen, University Medical Center Groningen, Hanzeplein 1, PO Box 30 001, FA40, 9700, RB, Groningen, The Netherlands

Full list of author information is available at the end of the article
}

(c) The Author(s). 2018 Open Access This article is distributed under the terms of the Creative Commons Attribution 4.0 International License (http://creativecommons.org/licenses/by/4.0/), which permits unrestricted use, distribution, and reproduction in any medium, provided you give appropriate credit to the original author(s) and the source, provide a link to the Creative Commons license, and indicate if changes were made. The Creative Commons Public Domain Dedication waiver (http://creativecommons.org/publicdomain/zero/1.0/) applies to the data made available in this article, unless otherwise stated. 


\section{Background}

Participation in voluntary work can have several individual and societal benefits. It is inversely related to mortality [1, 2] depression [2, 3] and functional limitations [3], and positively related to self-rated health [3]. In turn, improved individual health is reflected in more societal sustainability, for example in terms of health care systems [4]. Furthermore, societal benefits of volunteering include increases in social solidarity and individuals' involvement in society [5] as well as economic benefits, for example in terms of contributions to Gross Domestic Product levels [6]. Because of the various socioeconomic benefits of volunteering and because of the current challenges faced by many developed countries related to population ageing, many policy measures are aimed nowadays at increasing participation rates in volunteering. In order to effectively target potential volunteers and to utilize the benefits related to volunteering, there is a need to understand the key factors related to participation in voluntary work. One important set of key factors are socio-demographic characteristics. By socio-demographic characteristics we mean characteristics that signify an individual's position in society. This includes indicators of an individual's position in the family domain (such as partner status and social network integration), the economic domain (such as education and income) and in the health domain (such as wellbeing). All these socio-demographic characteristics are examples of factors for which an association with volunteering is expected. Our research questions are:

1. What are the determinants (e.g. sociodemographic characteristics) of participation in voluntary work?

2. What is the magnitude and direction of the relationship between identified determinants (e.g. socio-demographic characteristics) and participation in voluntary work?

Voluntary work is defined as "unpaid non-compulsory work; that is, time individuals give without pay to activities performed either through an organization or directly for others outside their own household" [5]. Research on factors influencing participation in voluntary work is extensive. However, there is large heterogeneity in the determinants measured as well as in the findings. Inconsistencies in findings may result from, among other factors, the use of incomparable study samples, the use of different study designs and the omission of important confounders in analyses. By conducting a systematic review and meta-analysis, sources of heterogeneity in the findings can be further explored and reliable key factors influencing participation in voluntary work can be identified.

Although earlier systematic reviews on determinants of participation in voluntary work provide important contributions to the knowledge on factors related to volunteering, most of them focussed on study samples consisting exclusively of volunteers recruited at voluntary organizations [7, 8], older people, [7] or volunteers working for a specific cause (i.e. volunteering in the care of people with mental illnesses) [8]. Moreover, both reviews included studies using diverse study designs (both quantitative as well as qualitative), and findings were not quantified [7, 8]. Wilson [9] provided an overview of theories explaining volunteerism and described several well-known determinants of volunteering, including level of education (positive association), age (curvilinear relationship), gender (in North-America, women are more likely to volunteer than men), marital status (married people are more likely to volunteer than non-married people) and health status (positive relationship). As the overview is based on literature published up until the year 2000, the findings did not result from conducting a review following a systematic approach, and associations were not quantified by conducting meta-analyses, there is need for updating the knowledge on the determinants of participation in voluntary work. Our aim was to improve the current knowledge by conducting a systematic review including a meta-analysis. Thereby, we aimed at summarizing the available evidence on the determinants of participation in voluntary work and determining the magnitude and direction of the relationship between identified determinants and participation in voluntary work.

\section{Methods}

This systematic review was conducted according to the methods of the Cochrane Collaboration [10] and reported according to the PRISMA (Preferred Reporting Items for Systematic Reviews and Meta-Analyses) guidelines [11].

\section{Search strategy and study selection}

A search was conducted in MEDLINE, PsychINFO, SocINDEX, Business Source Premier and EconLit, on August 12th, 2015. The search strategy included a combination of terms related to (a) participation in voluntary work (e.g. voluntary work, volunteers, unpaid work) and (b) determinants (e.g. determinant, factor, association, relation, reason) (see Appendix 1).

Articles were selected if they are (a) peer-reviewed full text publications reporting an association between at least one individual factor (contextual factors are beyond the scope of this study) and participation in formal voluntary work (i.e. voluntary work carried out 
for organizations [12]) (yes/no) in a quantitative way using a longitudinal prospective cohort study design (i.e. studies in which the determinant is measured at a moment in time before the outcome was measured), and (b) making use of a study sample consisting of adults aged 18 and over from a general population from a developed country (i.e. Japan and countries in Europe, North America and Oceania). Moreover, (c) the article has to be published in English, French, German or Dutch within the time period 2010-2015. Given the large number of publications on the topic, we decided to focus on recent publications from 2010 onwards. Articles exclusively including informal volunteering as the outcome were excluded. In case it is unclear whether volunteering was formal or informal, articles were included and labelled as 'mixed type of voluntary work'. Finally, articles focusing on very specific cases of volunteering such as disaster volunteering, corporate volunteering and volunteer-tourism were excluded as well, because of their limited comparability with volunteering in the general population, but also because the motives to participate in these kinds of voluntary work may differ from situation to situation. We focus on longitudinal rather than on cross-sectional studies, as the former offer better opportunities for temporal ordering of factors.

The titles and abstracts of all identified records were screened for eligibility by two reviewers (J.N. and L.v.L.) independently. Subsequently, the same two reviewers independently screened the full-text of all potentially eligible articles. Finally, all references of included articles were screened by one reviewer (J.N.) for potentially eligible articles.

\section{Data extraction and assessment of risk of bias}

Two reviewers (J.N. and L.v.L.) independently extracted the data regarding the characteristics of the study sample (country, mean age, \% female, inclusion criteria), the year of baseline measurement, study duration, determinant measurement, outcome measurement, sample size, volunteering at baseline (\%), volunteering at follow-up (\%), and the results (association between the determinant(s) and the outcome). The same two reviewers independently assessed the risk of bias of the included articles by using the QUIPS (Quality In Prognosis Studies) tool [13]. The following domains were assessed as potential sources for risk of bias: study participation, study attrition, measurement of the determinants and the outcome, study confounding and statistical analysis and reporting (see Appendix 2). Overall disagreement was evaluated and expressed as percentage of agreement and kappa statistics [14]. In a consensus meeting disagreements were discussed and resolved. If consensus could not be reached, a third reviewer (N.Sm.) made the final decision.

\section{Statistical analysis}

In case the results of at least two studies are available, meta-analyses were conducted, using the statistical program Comprehensive Meta-Analysis (3rd version). If studies present several models, estimates from the most complete (fully adjusted) model were used. Odds Ratios (ORs) with 95\% Confidence Intervals (CIs) were used, or if needed calculated using the supplemental material of Kuiper et al. [15], to conduct meta-analyses. When insufficient information was available for transforming effect sizes to ORs with $95 \%$ CIs, study authors were contacted to obtain the missing information.

In case articles used the same study sample, a-priori defined criteria were used to select the study for the meta-analysis. In order of importance and for each determinant separately, articles were selected based on (a) outcome used in the study ('formal voluntary work' was preferred above 'mixed type of voluntary work'), (b) measurement of the determinant (the determinant measurement was most comparable to other included studies), (c) study sample (the study sample that was the most comparable to the study samples of included studies in the meta-analysis, in terms of the proportion of volunteers at baseline, the age range of participants at baseline, and inclusion criteria for the baseline study sample), (d) sample size (the study with the largest sample size was preferred over smaller studies), and (e) number of determinants quantitatively measured in the study. In case articles presented both a static (e.g. being married) as well as a change score (e.g. transition into marriage) for a certain determinant, the score that is most comparable to the scores used in other included studies for this determinant was used. A random effect method was applied to calculate pooled effect sizes [10].

\section{Meta-regression and subgroup analyses}

Heterogeneity between studies was assessed by using the Index of Inconsistency $\left(I^{2}\right)$ [16]. In case of substantial heterogeneity $\left(I^{2}>50 \%\right)$, sources of heterogeneity between studies were explored by conducting either subgroup analysis (in case $<10$ studies are available) or univariable random-effects meta-regression [10] (in case $\geq 10$ studies are available) with regard to the following a-priori defined criteria: (a) outcome measurement (formal voluntary work versus mixed measure); (b) determinant measurement, based on (b1) measurement scale (continuous versus dichotomous scores), (b2) type of measurement (static versus change scores, because the presence of a certain event, (e.g. being married), may have a different association with the outcome than the 
transition into a certain event (e.g. transition into marriage)), and (b3) conceptual differences in the measurement of the determinant; (c) proportion of volunteers in the baseline study sample; (d) mean age at baseline, because some determinants may be important to a different extent for study samples for which participation in paid work is more or less common; (e) continent in which the study was performed (United States of America (USA), Europe, other), because differences in government regimes and culture may influence the association between a certain determinant and the outcome; (f) year of baseline measurement, because although the included studies were published between 2010 and 2015, the baseline measurement year varies substantially and determinants of participation in voluntary work may differ for different birth cohorts; (g) duration of follow-up (for time-variant variables only); and (h) the risk of bias for each methodological quality domain separately (low risk of bias versus high/unclear risk of bias).

\section{Publication bias}

The likelihood of publication bias was assessed graphically by constructing funnel plots for each determinant (in case at least ten studies were available) using the statistical program Comprehensive Meta-Analysis (3rd version). Asymmetry of the funnel plots was tested using Egger's method. Publication bias is likely if $p<0.10$ [17].

\section{Results}

The search resulted in the identification of 13.225 records after removing duplicates. A total of 3774 records were published in 2010 or later. The selection process is presented in Fig. 1. Finally, 24 articles were included in the systematic review [18-41]. Characteristics of the included articles are provided in Table 1. In Appendix 3 an overview of all determinants measured in included studies is provided.

Several articles were based on the same study samples. Four articles were based on data from the Survey of

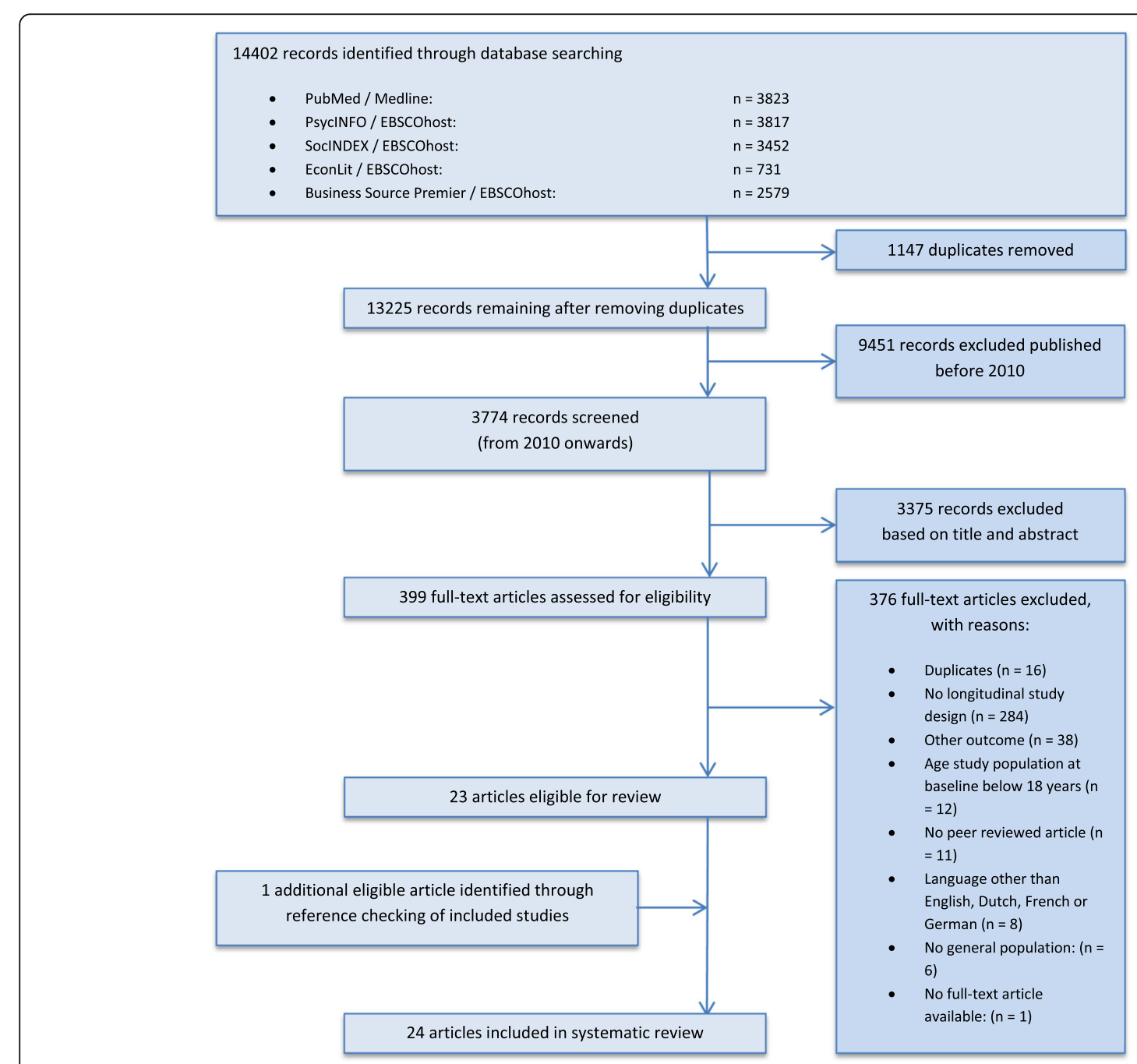

Fig. 1 Flow Diagram representing the selection process of articles 


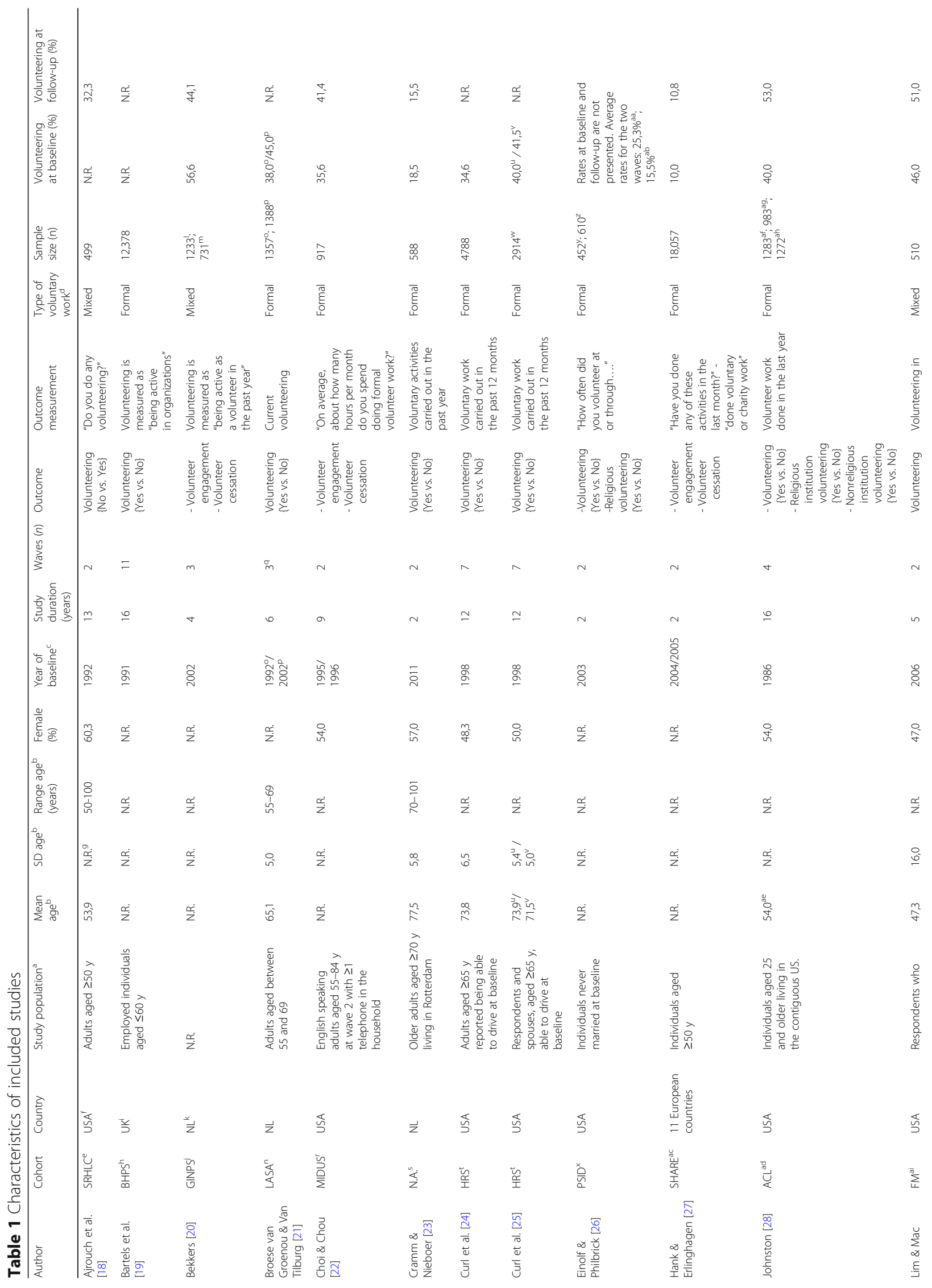




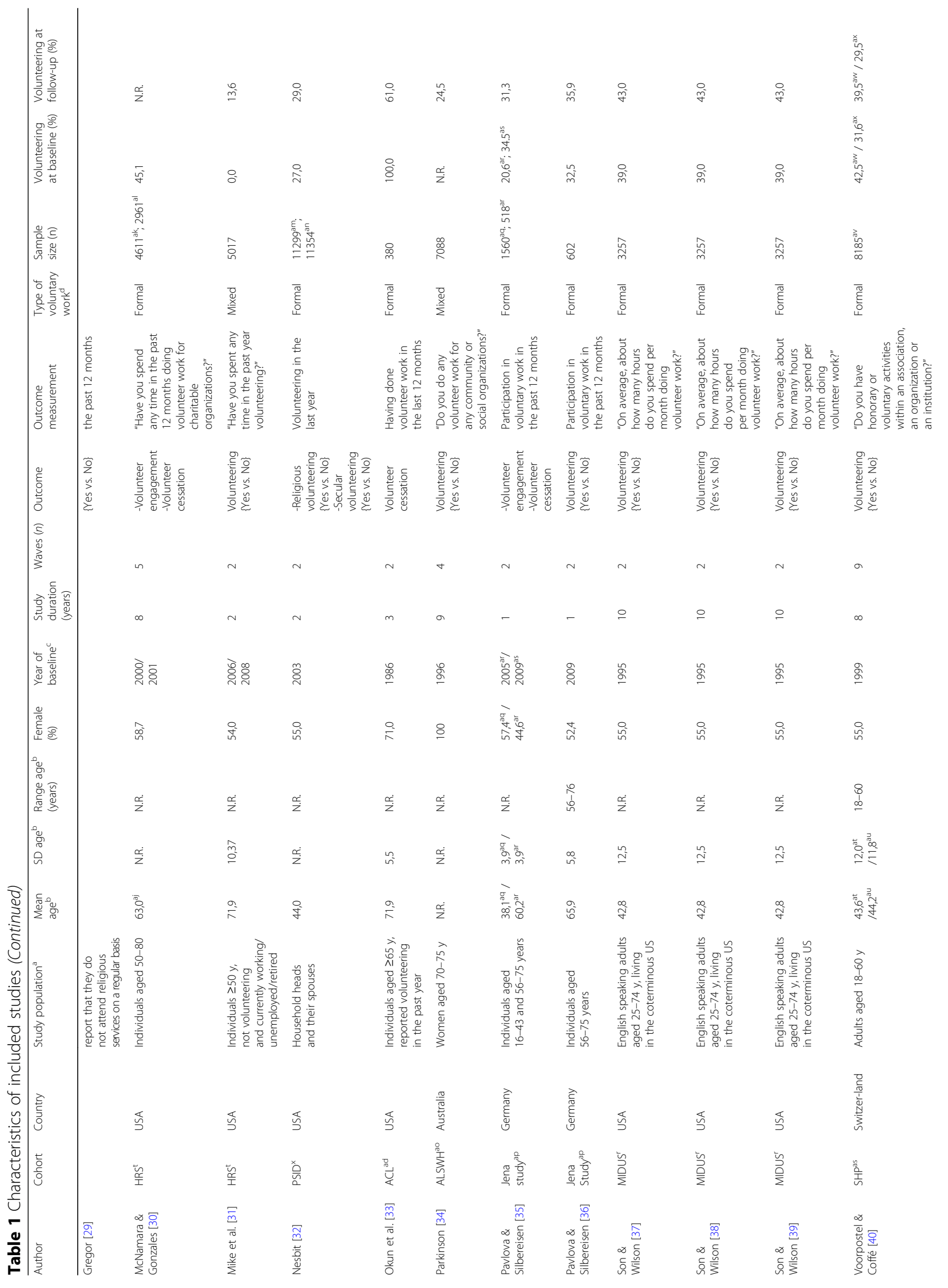




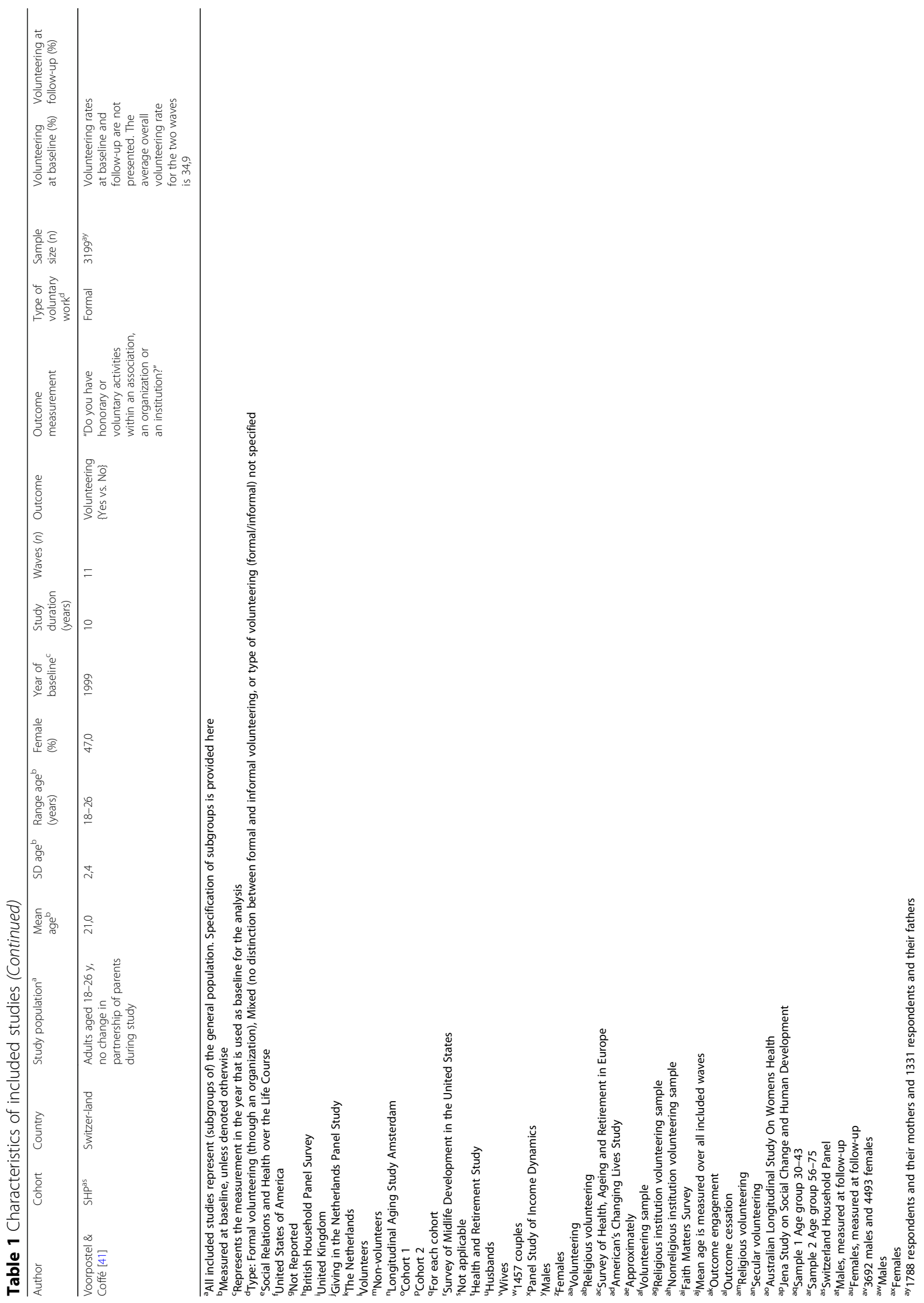


Midlife Development in the United States [22, 37-39]. Another four articles were based on data of the Health and Retirement Study [24, 25, 30, 31]. Two articles used data from the Jena Study on Social Change and Human Development [35, 36]. Moreover, two articles used data from the Switzerland Household Panel [40, 41]. Finally, two articles were based on the American Changing Lives survey $[28,33]$.

\section{Likelihood of risk of bias}

The results of the risk of bias assessment of included studies are presented in Table 2.

The risk of bias varied substantially. Most methodological flaws (i.e. high risk of bias) were found for (2a) adequate follow-up rate (62.5\% high risk of bias), and (1b) adequate participation rate (29.2\% high risk of bias). The inter-rater agreement was good (agreement $91.7 \%$ (484/528); kappa statistic: 0.78) [14].

\section{Determinants of participation in voluntary work}

Meta-analyses were conducted for a total of 20 determinants (see Appendix 4). For each determinant, all studies reporting an association between the determinant and the outcome are listed in the appendix, as well as the studies selected for inclusion in the meta-analysis.

\section{Demographic factors}

The following demographic factors are studied in relationship to participation in voluntary work: age, gender, ethnicity, marital status and parental status. Forest plots for all demographic factors are presented in multi panel Fig. 2 below.

Age The mean age at baseline of the studies included in the meta-analysis varied from 42.8 years (range 25 to 74 years) [39] to 77.5 years (range 70 to 101 years) [23]. The results of the meta-analysis are heterogeneous (see Fig. 2a). Six studies [11, 21, 24, 26, 30, 36] (out of eleven) found that older people are less likely to volunteer, no associations in the opposite direction were found. Sources of heterogeneity were explored by conducting meta-regression analyses and subgroup analyses (see Table 3 ).

The meta-regression shows that differences in the proportion of volunteers in the baseline sample affect the association between age and participation in voluntary work. The negative coefficient from the meta-regression $(-0.8053, p=0.000)$ shows that the inverse association between age and the likelihood to volunteer is stronger in the non-volunteer sample than in the subgroup of samples in which the proportion of volunteers lies between 0 and $100 \%$. Therefore, the results indicate that the likelihood to participate in voluntary work declines with age, and that especially the likelihood to take-up voluntary work (for individuals not volunteering at baseline) strongly decreases with age.

Gender (female) Two studies (out of eleven) included in the meta-analysis did not report the percentage of females in the baseline study sample [21, 27]. The percentage of females in the baseline study samples of the other included studies ranged from $44.6 \%$ [32] to $71.0 \%$ [33] (heterogeneous results; see Fig. 2b).

The results of the meta-regression (Table 4) showed that differences in the continent (Europe versus USA) of the study sample explain heterogeneity in the association between gender and participation in voluntary work.

The negative coefficient $(-0.3531 ; p=0.002)$ from the meta-regression for Europe (USA as reference group) shows that the likelihood of females (as opposed to males) to participate in voluntary work is higher in the USA than in Europe. In the studies conducted in the USA [18, 24, 29, 32, 33, 39], a positive association between being female and participation in voluntary work was found (OR: 1.279; 95\% CI: 1.120-1.460; results are heterogeneous $\left.\left(I^{2}=52 \%\right)\right)$. In the studies conducted in Europe [21, 23, 27, 35, 41], no association between gender and participation in voluntary work was found (OR: 0.906; 95\% CI: 0.770-1.067; results are heterogeneous $\left.\left(I^{2}=77 \%\right)\right)$. Having a closer look at the subgroups of studies conducted in the USA and in Europe shows that (a) in Europe no consistent association between gender and participation in voluntary work was found (both positive as well as negative associations between gender and participation in voluntary work were found) whereas (b) in the subgroup of studies conducted in the USA, all odds ratios for the association between being female and participation in voluntary work are greater than one, indicating a greater likelihood of females (as opposed to males) to participate in voluntary work.

Ethnicity (white) The results of the studies investigating the association between ethnicity and participation in voluntary work are heterogeneous and inconsistent (see Fig. 2c).

Heterogeneity could be explained by conducting subgroup analyses for differences in (a) year of baseline measurement (no association for the studies with a baseline measurement after 2005 [23, 29] (OR: 1.743; 95\% CI: $0.308-9.877$ ) and (b) the risk of bias for the domain study participation (no association for the studies with low risk of bias [18, 39] (OR: 1.101; 95\% CI: 0.929-1.034). Forest plots are available upon request.

Marital status (married/partnered) The results of the meta-analysis for marital status are heterogeneous and inconsistent (see Fig. 2d). 


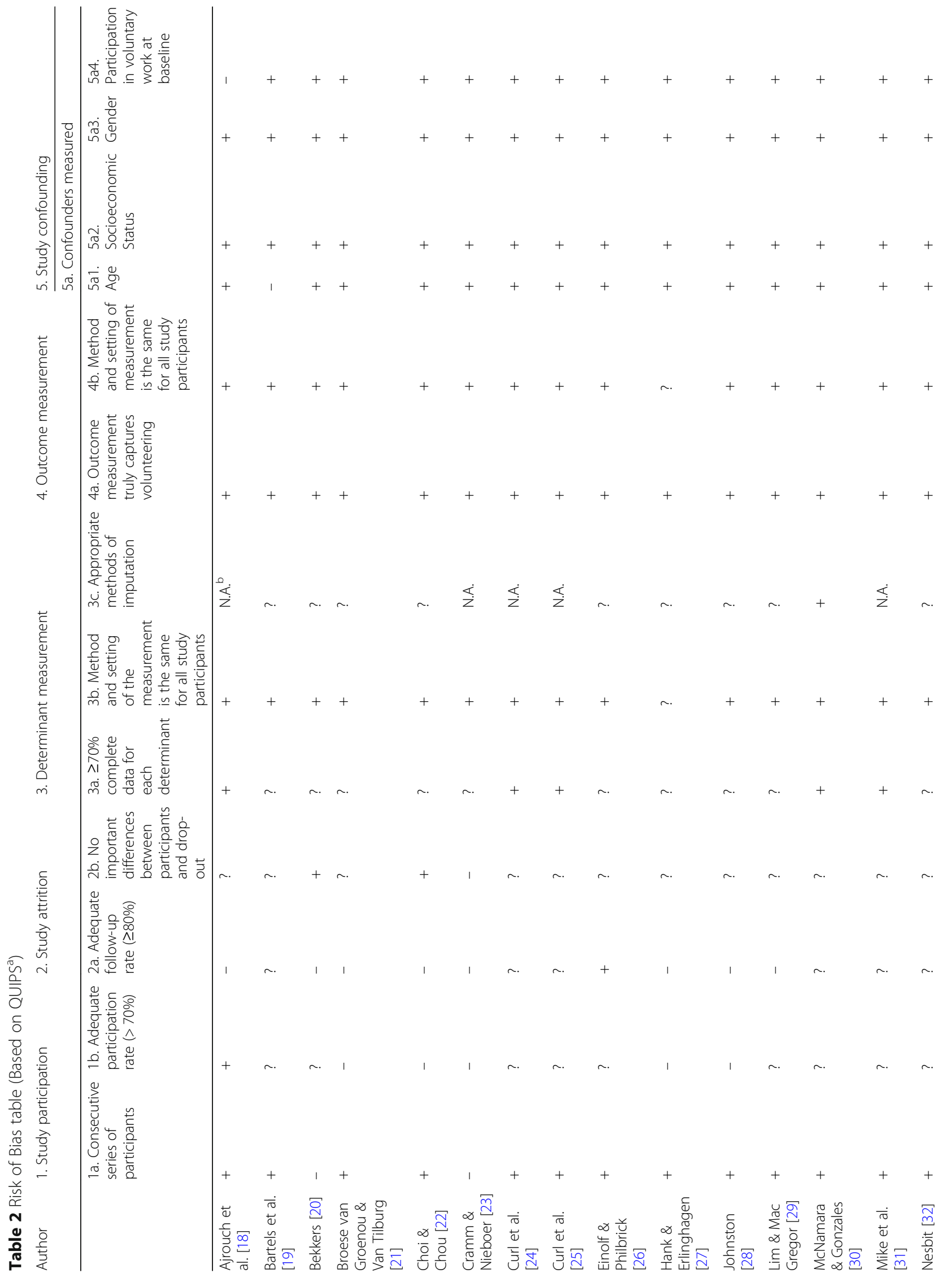




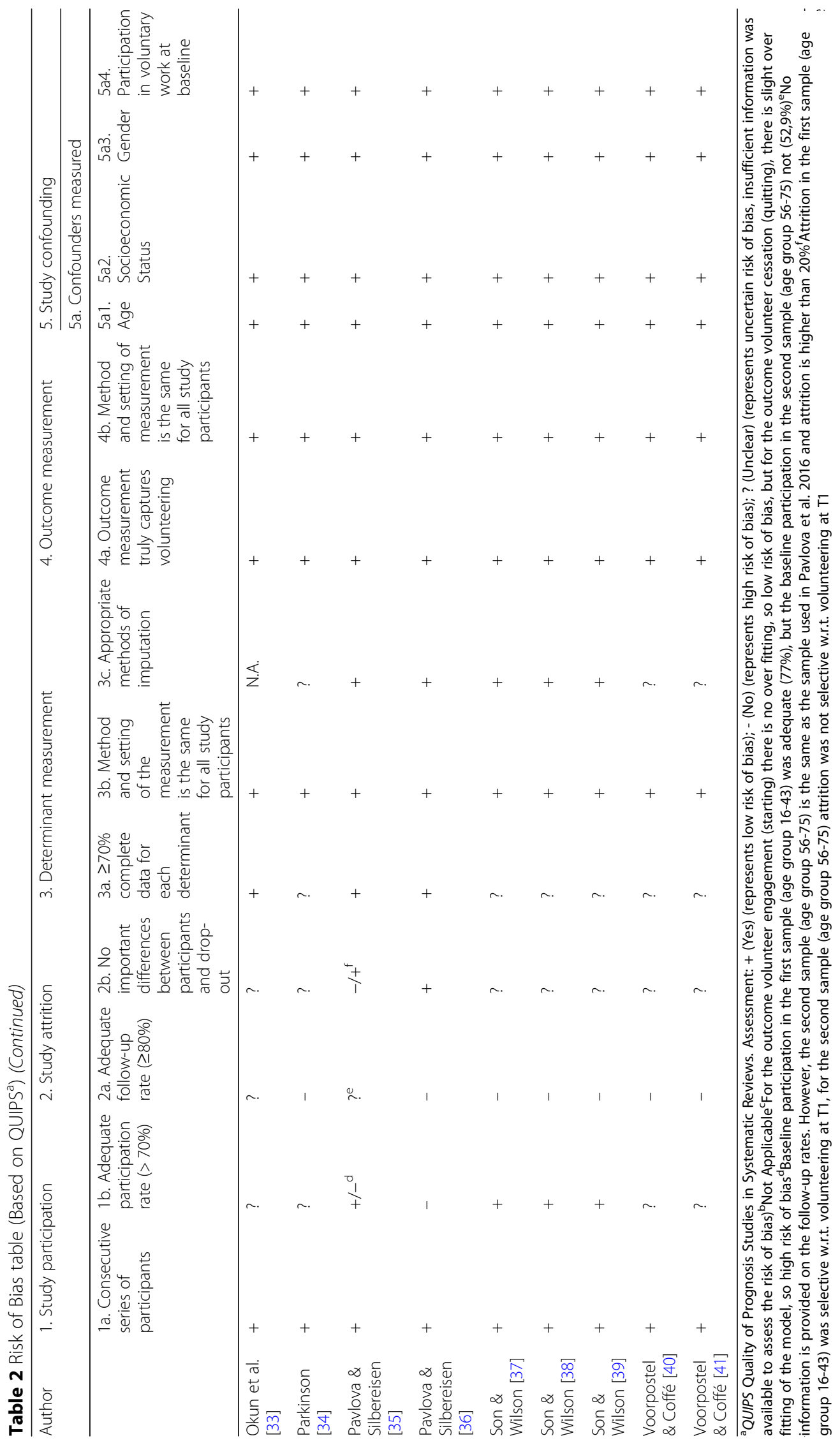




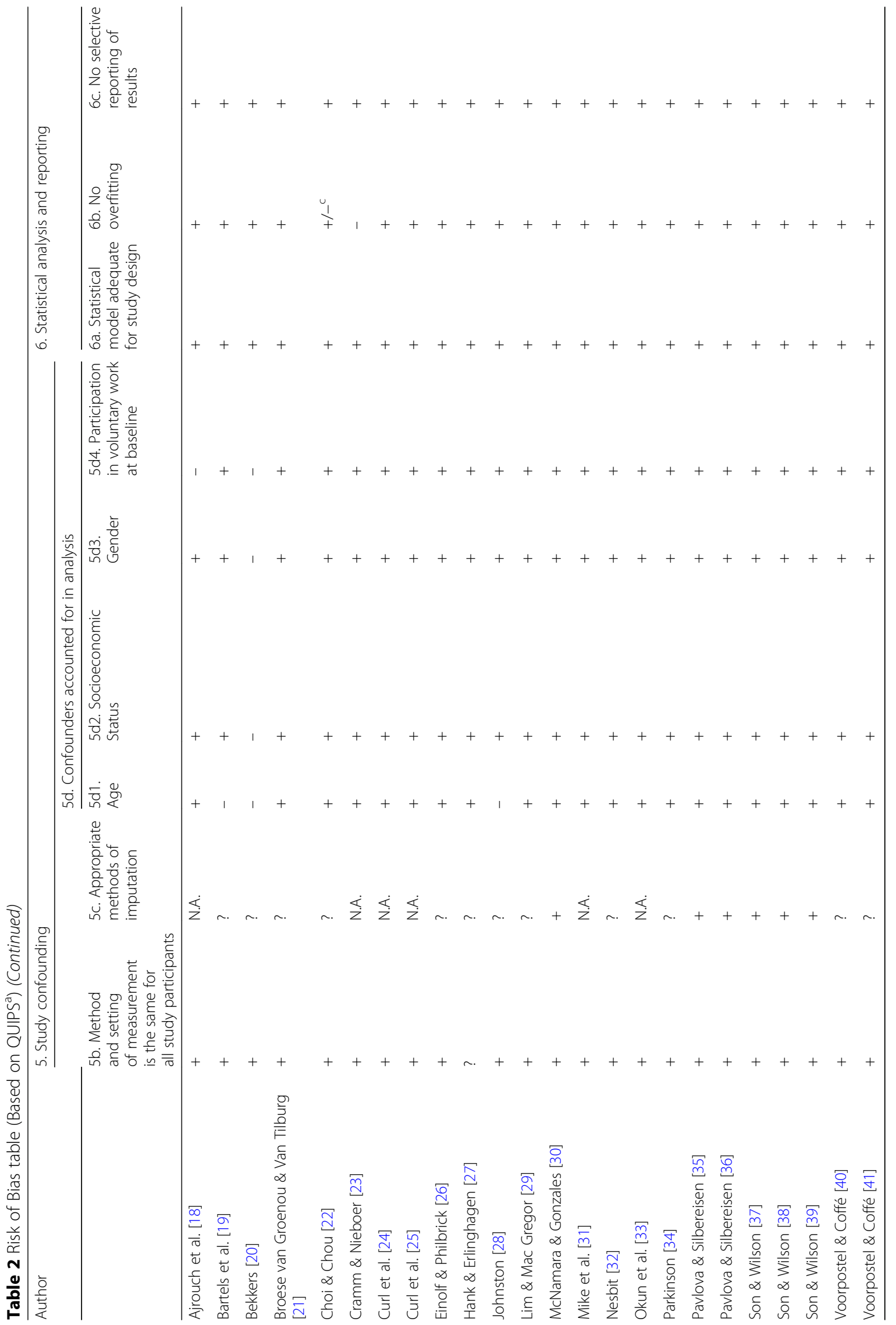




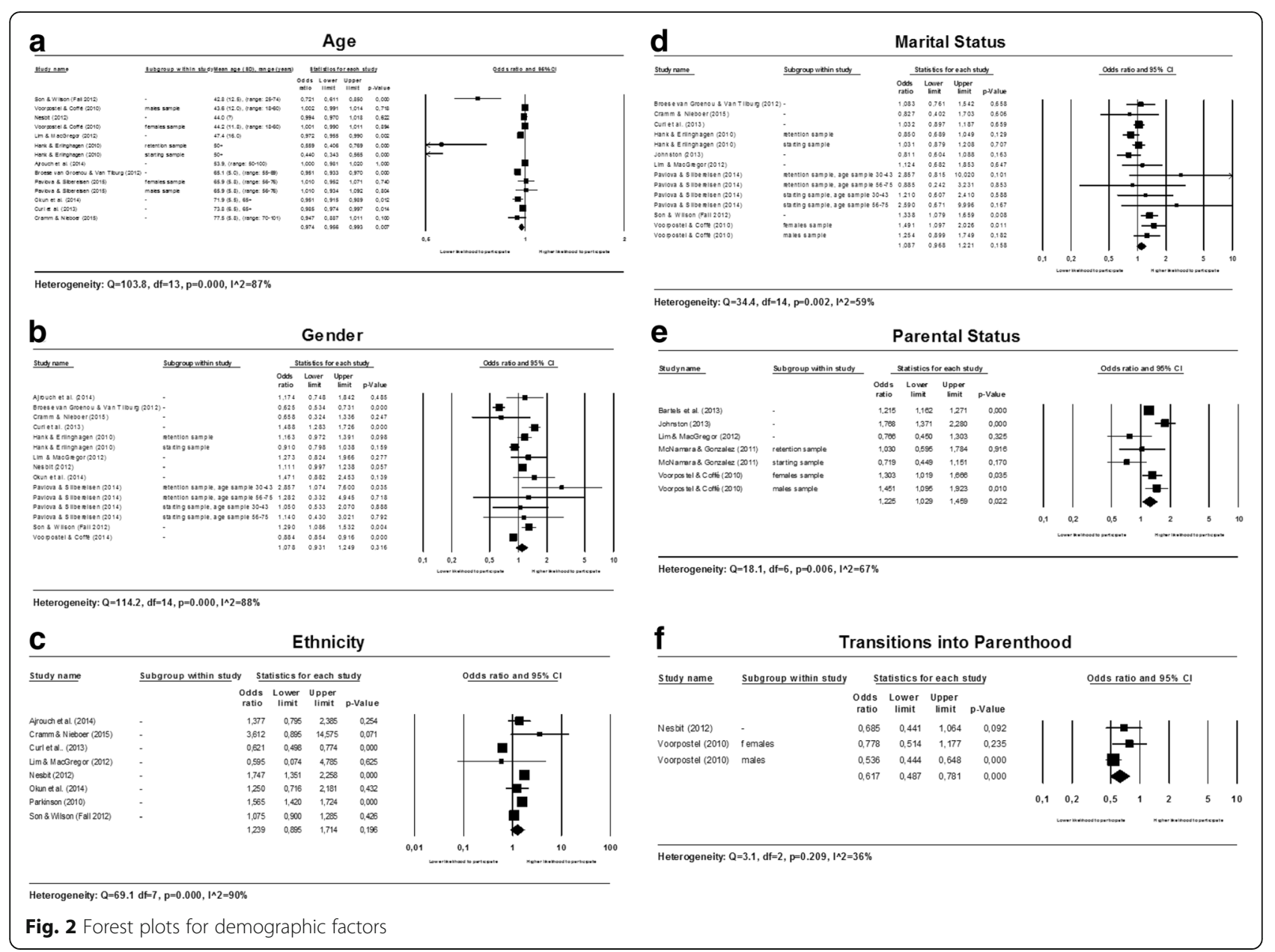

Sources of heterogeneity were explored by conducting meta-regression and subgroup analyses (see Table 5).

The results of the meta-regression show that differences in (a) mean age at baseline and (b) the risk of bias for the domains study participation and study confounding affect the association between marital status and participation in voluntary work.

Firstly, the pooled estimate of the subgroup of the eight studies [21, 23, 24, 28, 29, 35, 39, 40] for which information on the mean age at baseline is available, shows that married people are more likely to participate in voluntary work than unmarried people (OR: 1.147; 95\% CI: 1.001-1.315; results are homogenous $\left.\left(I^{2}=35 \%\right)\right)$. The negative coefficient $(-0.0008 ; p=0.030)$ from the metaregression shows that the positive association between being married and participation in voluntary work declines with age; i.e. being married as a determinant of participation in voluntary work declines in importance with age.

Secondly, the positive coefficients from the meta-regression for the risk of bias domains study participation $(0.3106 ; p=0.047)$ and study confounding $(0.2803 ; p=$
0.012) show that the association between being married and participation in voluntary work is stronger in studies with low risk of bias on these domains than for the studies with unclear/high risk of bias.

Although we did not find an overall association between marital status and participation in voluntary work, several subgroups of studies point towards a positive association between being married/partnered and the likelihood to volunteer. The meta-regression shows that as age increases, the association between being married/ partnered and the likelihood to participate in voluntary work gets less strong. Our findings are in line with earlier research, showing that being married is positively associated to participation in voluntary work; but associations between marital status and volunteering after retirement are inconsistent [9].

Parental status The results of the studies investigating the association between parental status and participation in voluntary work are heterogeneous (see Fig. 2e). Heterogeneity could not be explained by conducting 
Table 3 Univariate random effects meta-regression (methods of moments) and subgroup analyses for AGE

\begin{tabular}{|c|c|c|c|c|c|c|c|c|c|}
\hline \multirow[b]{3}{*}{ Variable } & \multirow[b]{3}{*}{ Subgroup } & \multirow[b]{3}{*}{ Number of studies } & \multicolumn{4}{|c|}{ Subgroup analyses } & \multicolumn{3}{|c|}{ Results from meta-regression } \\
\hline & & & \multicolumn{2}{|c|}{ Results } & \multicolumn{2}{|c|}{ Heterogeneity } & \multirow[b]{2}{*}{ Coefficient } & \multirow[b]{2}{*}{ SD } & \multirow[b]{2}{*}{$P$-value } \\
\hline & & & OR & $95 \% \mathrm{Cl}$ & $P$-value & $P^{2}$ & & & \\
\hline \multirow[t]{2}{*}{ Outcome measurement } & Mixed & 2 & 0.986 & $0.959-1.013$ & 0.037 & $77 \%$ & Reference & & \\
\hline & Formal & 9 (12 different samples) & 0.969 & $0.946-0.992$ & 0.000 & $89 \%$ & -0.0168 & 0.0251 & 0.504 \\
\hline \multirow[t]{2}{*}{ Determinant measurement } & Dichotomous & 1 (2 different samples) & 0.485 & $0.385-0.611$ & 0.248 & $25 \%$ & Reference & & \\
\hline & Continuous & 10 (12 different samples) & 0.983 & $0.969-0.996$ & 0.000 & $78 \%$ & 0.7122 & 0.1014 & 0.000 \\
\hline \multirow{4}{*}{$\begin{array}{l}\text { Proportion of volunteers } \\
(\%) \text { in baseline study sample }\end{array}$} & Continuous & $10^{\mathrm{a}}$ (13 different samples) & 0.970 & $0.950-0.991$ & 0.000 & $88 \%$ & 0.0000 & 0.0001 & 0.591 \\
\hline & $0-100 \%$ & 9 (11 different samples) & 0.985 & $0.971-0.999$ & 0.000 & $79 \%$ & Reference & & \\
\hline & $0 \%$ & 1 & 0.440 & $0.343-0.565$ & N.A. & N.A. & -0.8053 & 0.1292 & 0.000 \\
\hline & $100 \%$ & 2 & 0.747 & $0.444-1.256$ & 0.001 & $91 \%$ & -0.0500 & 0.0292 & 0.087 \\
\hline \multirow[t]{3}{*}{ Mean age at baseline } & Continuous & $10^{\mathrm{b}}$ (12 different samples) & 0.983 & $0.969-0.996$ & 0.000 & $78 \%$ & -0.0000 & 0.0000 & 0.200 \\
\hline & $\leq 55$ years & 5 (6 different samples) & 0.991 & $0.975-1.007$ & 0.000 & $79 \%$ & Reference & & \\
\hline & $>55$ years & 6 (8 different samples) & 0.944 & $0.904-0.986$ & 0.000 & $89 \%$ & -0.0296 & 0.0198 & 0.135 \\
\hline \multirow[t]{2}{*}{ Continent } & USA & 6 & 0.978 & $0.959-0.998$ & 0.001 & $77 \%$ & Reference & & \\
\hline & Europe & 5 (8 different samples) & 0.966 & $0.933-1.000$ & 0.000 & $91 \%$ & -0.0026 & 0.0210 & 0.900 \\
\hline \multirow[t]{3}{*}{ Year of baseline measurement } & Continuous & 11 (14 different samples) & 0.989 & $0.984-0.995$ & 0.000 & $87 \%$ & 0.0006 & 0.0014 & 0.686 \\
\hline & $<2006$ & 8 (10 different samples) & 0.970 & $0.948-0.993$ & 0.000 & $91 \%$ & Reference & & \\
\hline & $\geq 2006$ & 3 (4 different samples) & 0.975 & $0.959-0.991$ & 0.388 & $1 \%$ & 0.0110 & 0.0230 & 0.631 \\
\hline \multicolumn{10}{|l|}{ Risk of bias items } \\
\hline \multirow[t]{2}{*}{ Study participation } & $\begin{array}{l}\text { Unclear/high risk } \\
\text { of bias }\end{array}$ & 9 (12 different samples) & 0.975 & $0.956-0.995$ & 0.000 & $88 \%$ & Reference & & \\
\hline & Low risk of bias & 2 & 0.858 & $0.623-1.192$ & 0.000 & $93 \%$ & -0.0099 & 0.0315 & 0.754 \\
\hline \multirow[t]{2}{*}{ Study confounding } & $\begin{array}{l}\text { Unclear/high risk } \\
\text { of bias }\end{array}$ & 1 & 1.000 & $0.981-1.020$ & N.A. & N.A. & Reference & & \\
\hline & Low risk of bias & 10 (13 different samples) & 0.970 & $0.950-0.991$ & 0.000 & $88 \%$ & -0.0303 & 0.0331 & 0.360 \\
\hline
\end{tabular}

${ }^{a}$ The study of Ajrouch et al. (2014) is not included in this analysis, because the proportion of volunteers (\%) in the baseline study sample is not reported

${ }^{\mathrm{b}}$ The study of Hank \& Erlinghagen (2010) is not included in this analysis, because the mean age at baseline is not reported

subgroup analyses. Three studies [19, 28, 40] (out of five) found a positive association between having children and participation in voluntary work and no negative associations were found. Although no firm conclusion can be drawn from these results, the results seem to indicate that parents with children in their household are more likely to volunteer.

Two articles $[32,40]$ reported estimates for the association between a transition into parenthood and participation in voluntary work. The pooled estimate of these two studies shows that individuals who recently had a child were less likely to participate in voluntary work than individuals who did not experience the birth of a child in the household recently (OR: 0.617; 95\% CI: 0.487 to 0.781 ) (see Fig. 2f).

\section{Socioeconomic status}

Two factors related to socioeconomic status are studied in relationship to participation in voluntary work. Meta-analyses were conducted for educational attainment as well as income. The forest plots are presented in multi panel Fig. 3 below.

Educational attainment The results of the meta-analysis for educational attainment are heterogeneous (see Fig. 3a). Seven studies [18, 21, 24, 27, 32, 34, 39] (out of thirteen) found that higher educated individuals are more likely to participate in voluntary work, no associations in the opposite direction were found. Sources of heterogeneity were explored by conducting meta-regression and subgroup analyses (see Table 6).

Results show that the association between educational attainment and the likelihood to volunteer is stronger in (a) samples consisting of non-volunteers (compared to samples consisting of both volunteers and non-volunteers) (0.3080; $p=0.005$ ), (b) the study conducted in Australia (compared to studies from the USA) $(0.2164 ; p=0.039)$ and (c) studies with low risk of bias on the domain study participation (compared to studies with high/unclear risk of bias) $(0.1620 ; p=0.034)$. 
Table 4 Univariate random effects meta-regression (methods of moments) and subgroup analyses for GENDER (female)

\begin{tabular}{|c|c|c|c|c|c|c|c|c|c|}
\hline \multirow[b]{3}{*}{ Variable } & \multirow[b]{3}{*}{ Subgroup } & \multirow[b]{3}{*}{ Number of studies } & \multicolumn{4}{|c|}{ Subgroup analyses } & \multirow{2}{*}{\multicolumn{2}{|c|}{$\begin{array}{l}\text { Results from meta- } \\
\text { regression }\end{array}$}} & \multirow[b]{3}{*}{$P$-value } \\
\hline & & & \multicolumn{2}{|c|}{ Results } & \multicolumn{2}{|c|}{ Heterogeneity } & & & \\
\hline & & & OR & $95 \% \mathrm{Cl}$ & $P$-value & $\frac{P^{2}}{2}$ & Coefficient & SD & \\
\hline \multirow[t]{2}{*}{ Outcome measurement } & Mixed & 2 & 1.224 & $0.895-1.674$ & 0.800 & $0 \%$ & Reference & & \\
\hline & Formal & 9 (13 different samples) & 1.061 & $0.907-1.243$ & 0.000 & $89 \%$ & -0.1424 & 0.2379 & 0.550 \\
\hline \multirow{4}{*}{$\begin{array}{l}\text { Proportion of volunteers } \\
\text { (\%) in baseline study sample }\end{array}$} & Continuous & $9^{\mathrm{a}}$ (13 different samples) & 1.099 & $0.917-1.317$ & 0.000 & $89 \%$ & 0.0004 & 0.0003 & 0.177 \\
\hline & $0-100 \%$ & 8 & 1.038 & $0.805-1.268$ & 0.000 & $93 \%$ & Reference & & \\
\hline & $0 \%$ & 2 (3 different samples) & 0.918 & $0.808-1.043$ & 0.836 & $0 \%$ & -0.0689 & 0.2266 & 0.761 \\
\hline & $100 \%$ & 3 (4 different samples) & 1.306 & $1.000-1.705$ & 0.296 & $19 \%$ & 0.2926 & 0.2156 & 0.175 \\
\hline \multirow[t]{3}{*}{ Mean age at baseline } & Continuous & $10^{\mathrm{b}}$ (13 different samples) & 1.109 & $0.920-1.337$ & 0.000 & $86 \%$ & -0.0000 & 0.0006 & 0.952 \\
\hline & $\leq 55$ years & 6 (8 different samples) & 1.136 & $0.939-1.374$ & 0.000 & $85 \%$ & Reference & & \\
\hline & $>55$ years & 6 (7 different samples) & 1.023 & $0.765-1.367$ & 0.000 & $90 \%$ & -0.1296 & 0.1695 & 0.445 \\
\hline \multirow[t]{2}{*}{ Continent } & USA & 6 & 1.279 & $1.120-1.460$ & 0.063 & $52 \%$ & Reference & & \\
\hline & Europe & 5 (9 different samples) & 0.906 & $0.770-1.067$ & 0.000 & $77 \%$ & -0.3531 & 0.1135 & 0.002 \\
\hline \multirow{3}{*}{$\begin{array}{l}\text { Year of baseline } \\
\text { measurement }\end{array}$} & Continuous & $11^{\complement}(15$ different samples $)$ & 1.078 & $0.931-1.249$ & 0.000 & $88 \%$ & 0.0008 & 0.0126 & 0.951 \\
\hline & $<2006$ & 9 (11 different samples) & 1.083 & $0.924-1.270$ & 0.000 & $91 \%$ & Reference & & \\
\hline & $\geq 2006$ & 3 (4 different samples) & 1.084 & $0.775-1.516$ & 0.474 & $0 \%$ & -0.0301 & 0.2334 & 0.897 \\
\hline \multicolumn{10}{|l|}{ Risk of bias items } \\
\hline \multirow[t]{2}{*}{ Study participation } & Unclear/high risk of bias & 9 (11 different samples) & 1.025 & $0.871-1.205$ & 0.000 & $89 \%$ & Reference & & \\
\hline & Low risk of bias & 3 (4 different samples) & 1.288 & $1.094-1.515$ & 0.383 & $2 \%$ & 0.2436 & 0.1809 & 0.178 \\
\hline \multirow[t]{2}{*}{ Study confounding } & Unclear/high risk of bias & 1 & 1.174 & $0.748-1.842$ & N.A. & N.A. & Reference & & \\
\hline & Low risk of bias & 10 (14 different samples) & 1.073 & $0.922-1.250$ & 0.000 & $89 \%$ & -0.0898 & 0.3302 & 0.786 \\
\hline
\end{tabular}

${ }^{a}$ The studies of Ajrouch et al. (2014) and Voorpostel \& Coffé (2014) are not included in this analysis, because the proportion of volunteers (\%) in the baseline study sample is not reported

${ }^{b}$ The study of Hank \& Erlinghagen (2010) is not included in this analysis, because the mean age at baseline is not reported

'The study of Broese van Groenou \& Van Tilburg (2012) includes two different samples in the analyses. For one of the samples, the year of baseline measurement is 1992, for the other sample, the year of baseline measurement is 2002. No separate results for the two samples are provided. In this specific analysis, we took 1992 as the year of baseline measurement, although this actually only is the case for the first sample

Although the results for the subgroups were heterogeneous, the pooled estimate of most studies point towards a positive association between educational attainment and participation in voluntary work. No contradictory results are found. Therefore, the results indicate that it is likely that there is a positive association between educational attainment and the likelihood to volunteer and this positive association seems to be especially strong for volunteer take-up.

Income The meta-analysis for income gives heterogeneous results (see Fig. 3b). Two studies [24, 28] (out of six) found a positive association between income and participation in voluntary work, no associations in the opposite direction were found.

Subgroup analyses show that people with a higher income are more likely to participate in voluntary work if they are 55 years or older at baseline ((OR: 1.185; 95\% CI: 1.106 to 1.270$)[24,35]$ or if they are living in the USA (OR: $1.121,95 \%$ CI: 1.037 to 1.211 ) [24, 28, 29, 39]. For the studies with a low risk of bias on the domain study confounding (OR: 1.184; 95\% CI: 1.109 to 1.265) [24, 29,
$35,39]$ this positive association between income level and the likelihood to participate in voluntary work was confirmed. No association between income and participation in voluntary work was found in the other subgroups with homogeneous results. Forest plots are available upon request.

\section{Participation in productive activities}

Two factors related to participation in productive activities are studied in relationship to participation in voluntary work. Meta-analyses were conducted for participation in voluntary work at baseline and for employment status. The forest plots are presented in multi panel Fig. 4 below.

Volunteering at baseline Results for the meta-analysis are heterogeneous (see Fig. 4a) and heterogeneity could not be explained by subgroup analyses. However, the estimates of the included studies clearly show that volunteering at baseline is positively associated to participation at follow-up; all included studies found a positive association between volunteering at baseline and volunteering at 
Table 5 Univariate random effects meta-regression (methods of moments) and subgroup analyses for MARITAL STATUS (married/ partnered)

\begin{tabular}{|c|c|c|c|c|c|c|c|c|c|}
\hline \multirow[b]{3}{*}{ Variable } & \multirow[b]{3}{*}{ Subgroup } & \multirow[b]{3}{*}{ Number of studies } & \multicolumn{4}{|c|}{ Subgroup analyses } & \multicolumn{3}{|c|}{ Results from meta-regression } \\
\hline & & & \multicolumn{2}{|c|}{ Results } & \multicolumn{2}{|c|}{ Heterogeneity } & \multirow[b]{2}{*}{ Coefficient } & \multirow[b]{2}{*}{ SD } & \multirow[b]{2}{*}{$P$-value } \\
\hline & & & OR & $95 \% \mathrm{Cl}$ & $P$-value & $\overline{P^{2}}$ & & & \\
\hline \multirow[t]{2}{*}{ Outcome measurement } & Mixed & 1 & 1.124 & $0.682-1.853$ & N.A. & N.A. & Reference & & \\
\hline & Formal & 9 (14 different samples) & 1.053 & $0.931-1.192$ & 0.001 & $62 \%$ & -0.0650 & 0.3067 & 0.832 \\
\hline \multirow{4}{*}{$\begin{array}{l}\text { Proportion of volunteers } \\
(\%) \text { in baseline study sample }\end{array}$} & Continuous & $9^{a}$ (14 different samples) & 1.087 & $0.968-1.221$ & 0.045 & $43 \%$ & -0.0002 & 0.0002 & 0.385 \\
\hline & $0-100 \%$ & 8 (9 different samples) & 1.071 & $0.917-1.250$ & 0.001 & $70 \%$ & Reference & & \\
\hline & $0 \%$ & 2 (3 different samples) & 1.052 & $0.902-1.227$ & 0.381 & $0 \%$ & 0.0468 & 0.1907 & 0.806 \\
\hline & $100 \%$ & 2 (3 different samples) & 1.080 & $0.564-2.066$ & 0.175 & $43 \%$ & -0.1253 & 0.2095 & 0.550 \\
\hline \multirow[t]{3}{*}{ Mean age at baseline } & Continuous & $8^{\mathrm{b}}$ (12 different samples) & 1.147 & $1.001-1.315$ & 0.112 & $35 \%$ & -0.0008 & 0.0004 & 0.030 \\
\hline & $\leq 55$ years & 6 (8 different samples) & 1.140 & $0.911-1.427$ & 0.000 & $76 \%$ & Reference & & \\
\hline & $>55$ years & 5 (7 different samples) & 0.999 & $0.913-1.092$ & 0.539 & $0 \%$ & -0.1477 & 0.1419 & 0.300 \\
\hline \multirow[t]{2}{*}{ Continent } & USA & 4 & 1.065 & $0.870-1.304$ & 0.049 & $62 \%$ & Reference & & \\
\hline & Europe & 6 (11 different samples) & 1.054 & $0.904-1.230$ & 0.009 & $57 \%$ & -0.0106 & 0.1314 & 0.936 \\
\hline \multirow[t]{3}{*}{ Year of baseline measurement } & Continuous & 10 (15 different samples) & 1.055 & $0.937-1.188$ & 0.002 & $59 \%$ & 0.0088 & 0.0096 & 0.361 \\
\hline & $<2006$ & 8 (11 different samples) & 1.055 & $0.928-1.199$ & 0.000 & $69 \%$ & Reference & & \\
\hline & $\geq 2006$ & 3 (4 different samples) & 1.081 & $0.742-1.575$ & 0.522 & $0 \%$ & 0.0295 & 0.2251 & 0.896 \\
\hline \multirow[t]{4}{*}{ Duration of follow-up } & Continuous & 10 (15 different samples) & 1.055 & $0.937-1.188$ & 0.002 & $59 \%$ & -0.0111 & 0.0115 & 0.335 \\
\hline & $\leq 3$ years & 3 (7 different samples) & 0.990 & $0.830-1.180$ & 0.274 & $20 \%$ & Reference & & \\
\hline & $4-7$ years & 2 & 1.096 & $0.822-1.463$ & 0.905 & $0 \%$ & 0.0776 & 0.2315 & 0.737 \\
\hline & $\geq 8$ years & 5 (6 different samples) & 1.082 & $0.896-1.306$ & 0.000 & $81 \%$ & 0.0580 & 0.1499 & 0.699 \\
\hline \multicolumn{10}{|l|}{ Risk of bias items } \\
\hline \multirow[t]{2}{*}{ Study participation } & $\begin{array}{l}\text { Unclear/high risk of } \\
\text { bias }\end{array}$ & 9 (12 different samples) & 1.004 & $0.897-1.124$ & 0.019 & $52 \%$ & Reference & & \\
\hline & Low risk of bias & 2 (3 different samples) & 1.353 & $1.105-1.657$ & 0.478 & $0 \%$ & 0.3106 & 0.1563 & 0.047 \\
\hline \multirow[t]{2}{*}{ Study confounding } & $\begin{array}{l}\text { Unclear/high risk of } \\
\text { bias }\end{array}$ & 2 & 0.846 & $0.766-0.935$ & 0.763 & $0 \%$ & Reference & & \\
\hline & Low risk of bias & 8 (13 different samples) & 1.115 & $0.994-1.252$ & 0.083 & $38 \%$ & 0.2803 & 0.1113 & 0.012 \\
\hline
\end{tabular}

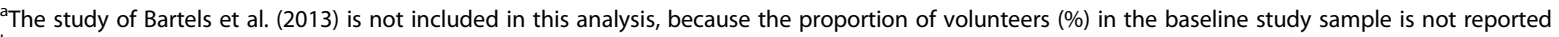

${ }^{\mathrm{b}}$ The studies of Bartels et al. (2013) and Hank \& Erlinghagen (2010) are not included in this analysis, because the mean age at baseline is not reported

follow-up. No firm conclusion can be drawn about the magnitude of the effect.

Employment status Results from the meta-analysis for employment status are homogeneous (see Fig. 4b). The pooled estimate shows no association between employment status and participation in voluntary work (OR: 0.880; $95 \%$ CI: 0.773 to 1.001$)$; however, the $p$-value of 0.053 shows that the association is boundary significant.

\section{Health status}

Five factors related to individual health status are studied in relationship to participation in voluntary work. Separate meta-analyses were conducted for overall self-rated health, (increase in) functional limitations, physical health, mental health and cognitive health. Forest plots for all factors related to individual health status are presented in multi panel Fig. 5 below.

Overall self-rated health The meta-analysis for overall self-rated health shows that results are heterogeneous (see Fig. 5a).

Heterogeneity between the results of the included studies could be explained by differences in (a) participation in voluntary work (\%) at baseline, (b) continent of the study sample and (c) duration of follow-up. The pooled estimate of the two studies $[24,39]$ with a baseline participation rate between $0 \%$ and $100 \%$, a long duration of follow-up ( $\geq 8$ years) and that are conducted in the USA shows that people with a better overall self-rated health are more likely to participate in voluntary work (OR: 1.192; 95\% CI: 1.137 to 1.249 ). Forest plots are available on request. 


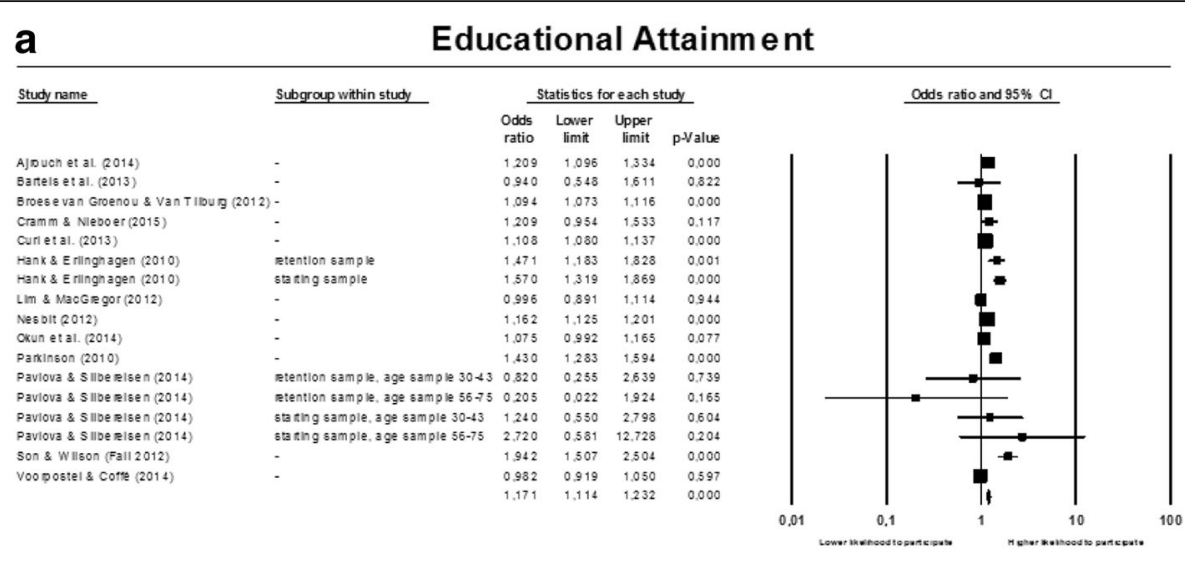

Heterogeneity: $Q=95.4 \mathrm{df}=16, \mathrm{p}=0.000, \operatorname{1\wedge } 2=83 \%$

b Income

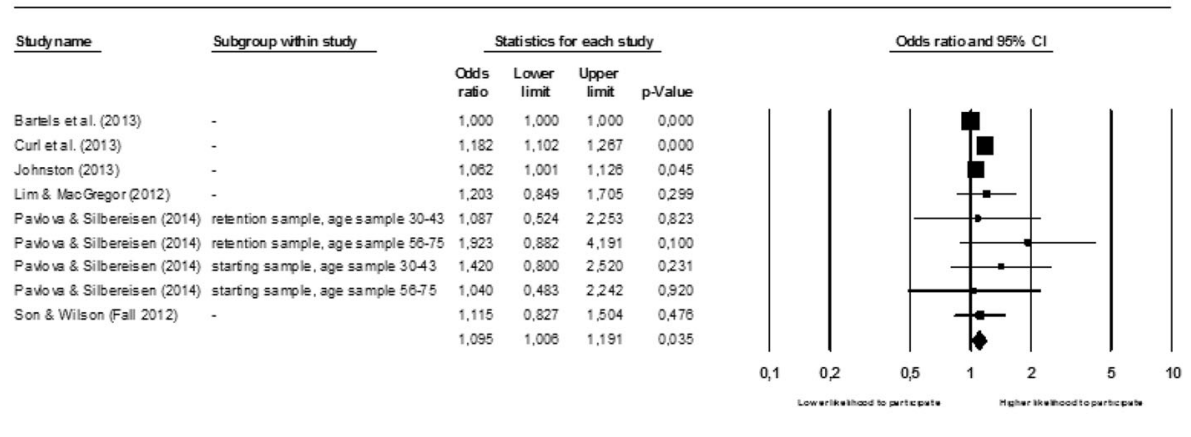

Heterogeneity: $Q=31.9 \mathrm{df}=8, \mathrm{p}=0.000, \mathrm{I}^{\wedge} 2=75 \%$

Fig. 3 Forest plots for socioeconomic factors

Functional limitations Three large studies [21, 24, 28] found a strong negative association between functional limitations and the likelihood to participate in voluntary work, one small study [18] did not find an association. Although the results are heterogeneous, the results clearly indicate that the degree of functional limitations is inversely associated with participation in voluntary work (see Fig. 5b).

The pooled estimates of the two studies [18, 28] for which the mean age at baseline was 55 years or below (OR: $0.740,95 \%$ CI: 0.636 to 0.860 ), the three studies [18, 24, 28] conducted in the USA (OR: 0.782; 95\% CI: 0.705 to 0.869$)$, and the two studies $[24,28]$ with a long duration of follow-up ( $\geq 8$ years) (OR: 0.781; 95\% CI: 0.695 to 0.877 ) consistently show that individuals with more functional limitations are less likely to participate in voluntary work. Forest plots are available on request.

Two studies $[18,21]$ reported an estimate for the association between an increase in the degree of limitations in functional health and participation in voluntary work (see Fig. 5c). The pooled estimate of these two studies shows that increases in functional limitations are associated with a lower likelihood to participate in voluntary work (OR: 0.922; 95\% CI: 0.887 to 0.959 ).

Physical health The results for the association between physical health and participation in voluntary work are heterogeneous (see Fig. 5d).

Pooling the estimates of the studies with formal volunteering as the outcome (as opposed to the mixed type of volunteering) and the estimates of the studies with low risk of bias on the domain study confounding leaves us with the same subgroup of two studies [23, 24]. No association between physical health and participation in voluntary work was found (OR: 1.013 ; $95 \% \mathrm{CI}: 0.985$ to 1.041 ) (forest plot is available on request).

Mental health and cognitive health For both mental health and cognitive health, the results for the association with participation in voluntary work are heterogeneous (see Fig. 5e and f). Heterogeneity could not be explained by conducting subgroup analyses. 


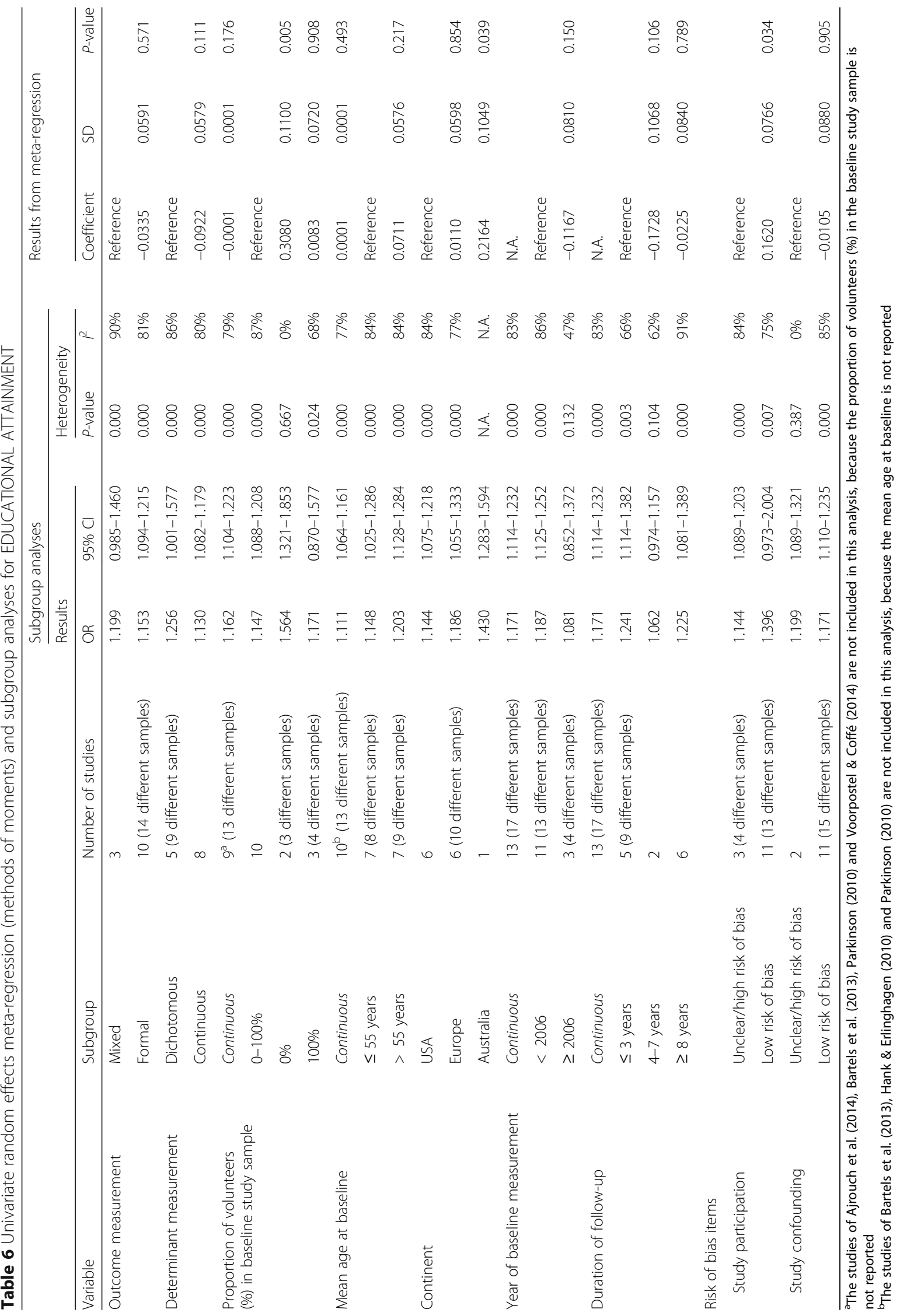




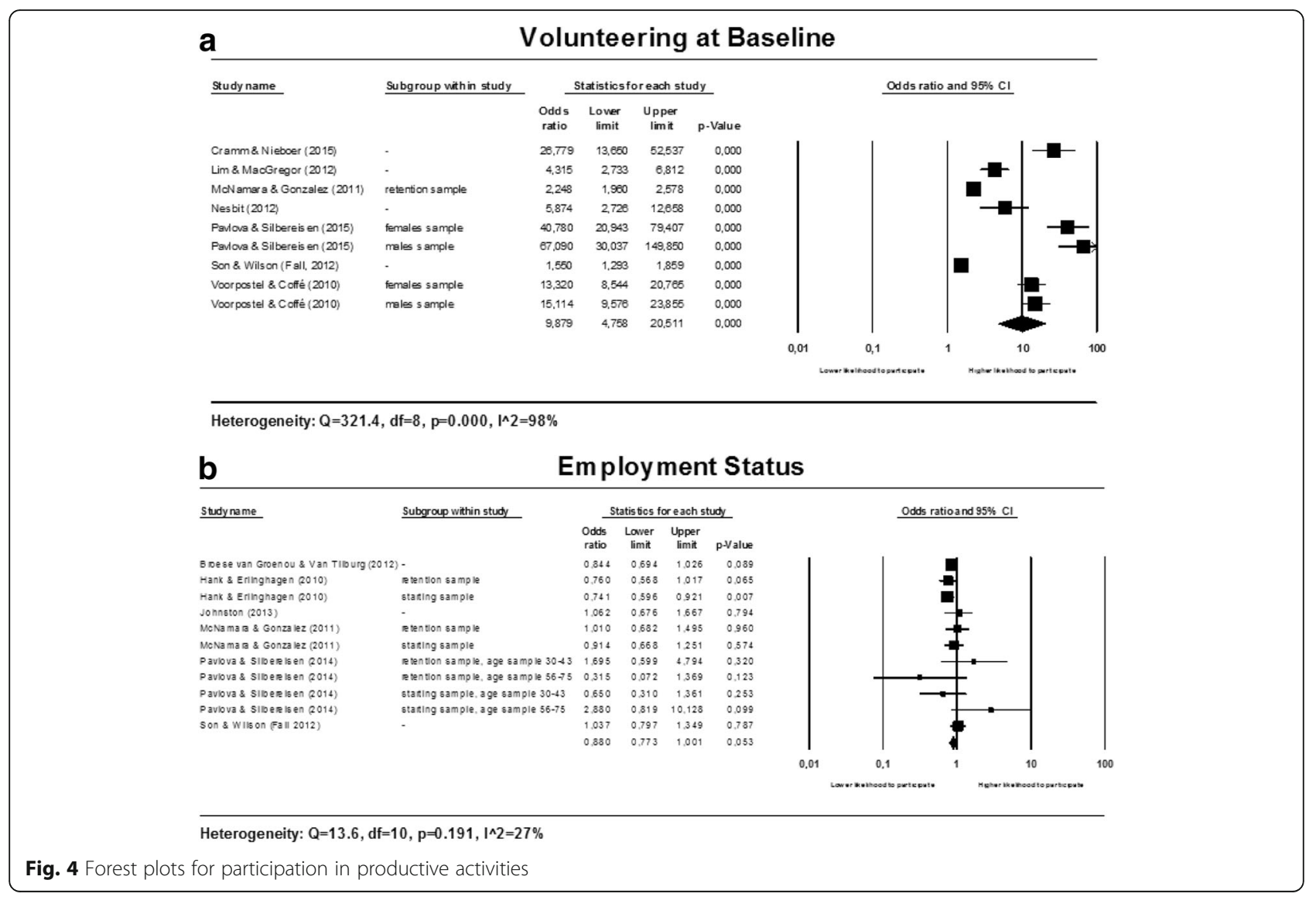

\section{Social relationships}

The social network size and frequency of contacts are studied in relationship to participation in voluntary work. Separate meta-analyses are conducted for both factors and the forest plots are presented in multi panel Fig. 6 below.

Social network size The pooled estimate shows that individuals with a larger personal social network are more likely to participate in voluntary work (OR: 1.030; 95\% CI: 1.030 to 1.030 ) (see Fig. 6a).

Frequency of contacts The results are heterogeneous and inconsistent (see Fig. 6b). Because of the large variety in the measures for frequency of social contacts used in the included studies, we did not conduct subgroup analyses to explore heterogeneity.

\section{Religion}

Two factors related to religion are studied in relationship to participation in voluntary work. Meta-analyses were conducted for church attendance and religious identification. Forest plots are presented in multi panel Fig. 7 below.
Church attendance The results for the association between church attendance and participation in voluntary work are heterogeneous (see Fig. 7a). Heterogeneity could not be explained by conducting subgroup analyses. However, all studies showed a positive association between church attendance and participation in voluntary work showing that church attendance and the likelihood to volunteer are positively associated. No firm conclusions can be drawn about the magnitude of the association.

Religious identification The pooled estimate showed a small positive association between the level of religious identification and participation in voluntary work (OR: 1.092; 95\% CI: 1.000 to 1.193) (see Fig. 7b).

\section{Other factors}

Two other factors are studied in relationship to participation in voluntary work. Results for the association between the frequency of attending meetings of groups, clubs and organizations (i.e. passive membership) and participation in voluntary work (i.e. active membership) are heterogeneous and inconclusive. The meta-analysis for driving status shows that people who are able to drive are more likely to participate in voluntary work. 


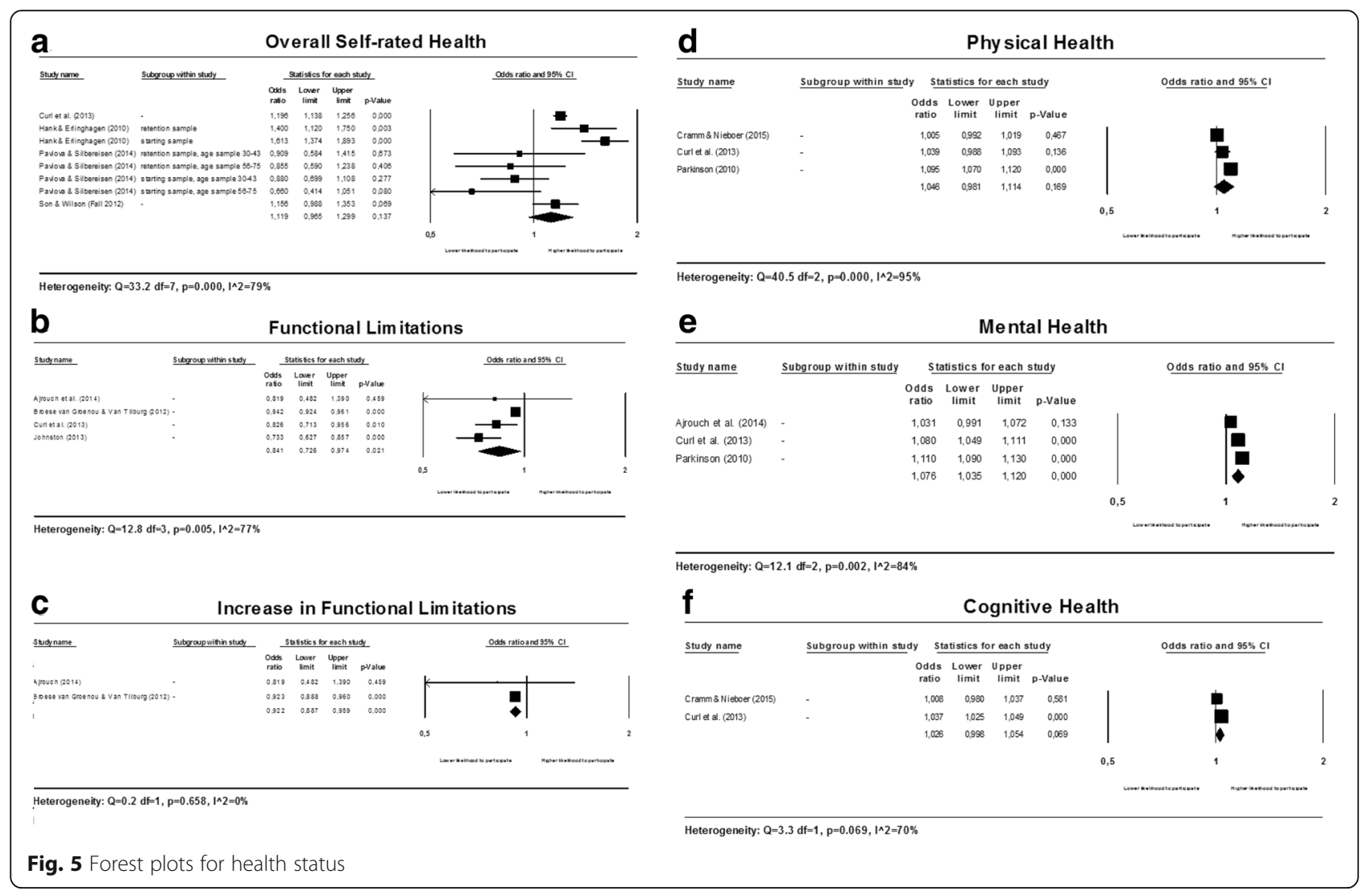

However, as the results are heterogeneous, no conclusions about the magnitude of the associations can be drawn. The forest plots are available upon request of the first author.

\section{Publication Bias}

Publication bias was assessed for the following determinants: age, gender, marital status and educational attainment. Eggers' test and visual inspection of the funnel plots indicate that publication bias is likely for the determinants age (Egger's test: age $(p=0.007)$ and marital status $(p=0.074)$ ). The funnel plots are available upon request.

\section{Discussion}

This systematic review and meta-analysis aimed at identifying the contemporary determinants of participation in voluntary work. Based on the studies included in our review, we found that females (in the USA), married people and people with children (weak evidence), individuals with higher education (weak evidence) or income (especially for those individuals aged 55 and over, living in the USA and for studies in which age was taken into account as a confounder) and people who either volunteered at baseline, have a larger social network, those who are more religious and those who attend church more frequently are more likely to volunteer. In contrast, older people (weak evidence), individuals who recently had a child and individuals with a higher degree of functional limitations or increases in functional limitations are less likely to participate in voluntary work. No association with participation in voluntary work was found for employment status. There was insufficient evidence to draw firm conclusions about the association between participation in voluntary work and gender outside the USA, ethnicity, the frequency of contacts and several health related variables (overall self-rated health, cognitive health and physical health) (inconclusive results).

Many of our findings are in line with what we expected based on previous literature. First, we found that older people are less likely to volunteer. Age is believed to be related to volunteering in a curvilinear way with a peak in middle-age [9]. The studies included in our meta-analysis for age all have a mean age around middle-age or above. The mean age at baseline among the studies included in this meta-analysis varies from 42.8 years (range 25 to 74 years) [39] to 77.5 years (range 70 to 101 years) [23] and adults aged below 40 years are underrepresented in this pool of studies. 


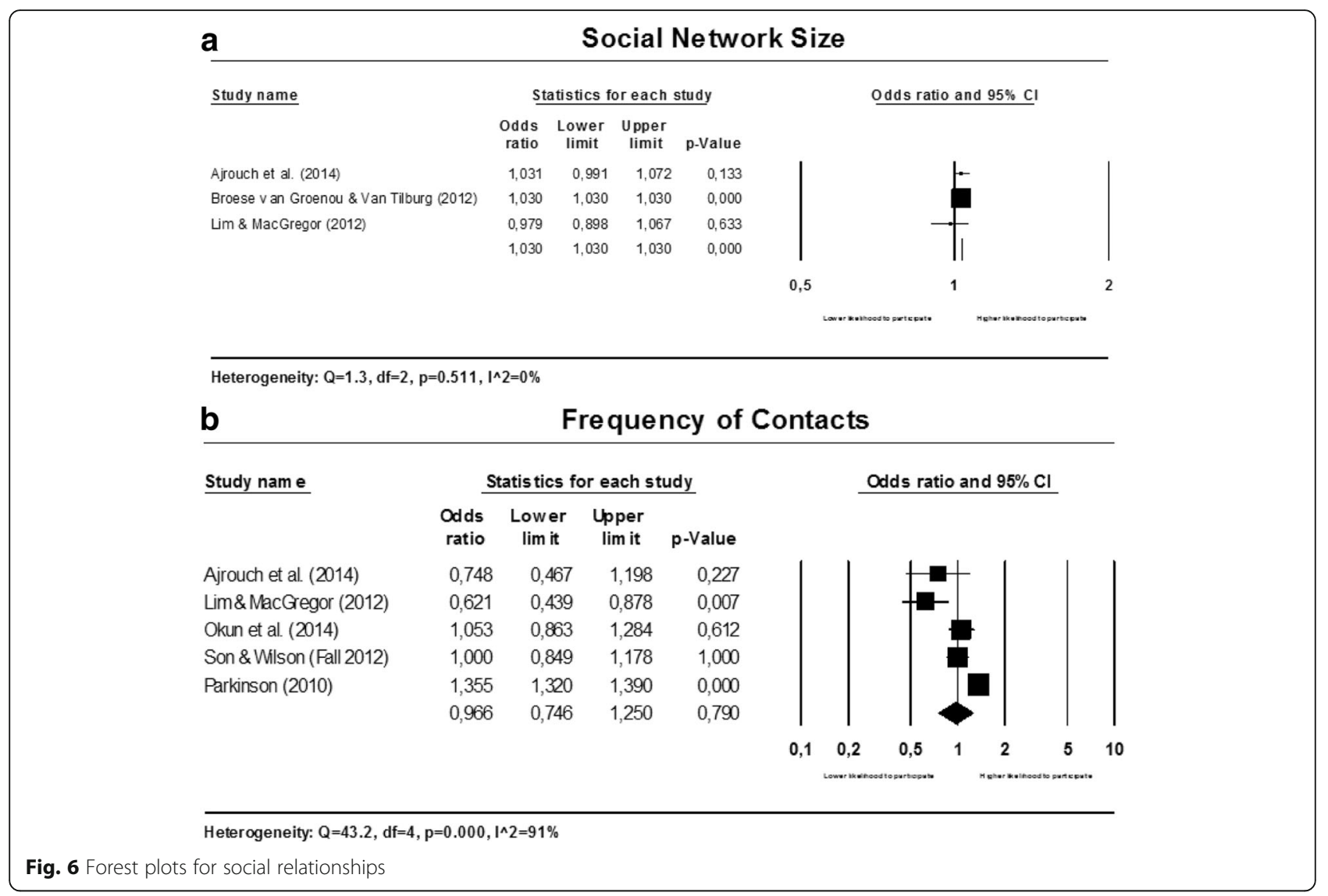

Therefore, our finding that age is inversely related to participation in voluntary work confirms previous findings that showed that the likelihood to volunteer declines with age from middle-age onwards. We could not assess the association between age and volunteering before middle-age because of the inclusion of middle-aged and older adults in the studies in this meta-analysis only.

Secondly, we found no association between gender and participation in voluntary work, but we did find a positive association between being female in the USA and participation in voluntary work. Thirdly, we found that irrespective of age, married people are more likely to participate in voluntary work than unmarried people, and that this association becomes weaker with age. Besides, our analyses confirmed the importance of education and previous volunteer experiences in predicting the likelihood to volunteer. Finally, our results show that individual health status itself is not associated to participation in voluntary work, but the degree to which the individual experiences limitation in his or her functioning is. Not only the level of functional limitations was shown to be inversely associated with participation in voluntary work, also for increases in functional limitations a strong negative association with volunteering was found.

Our systematic review shows that a large number of individual factors are related to volunteering across studies and countries. Although a discussion of the theoretical links between these factors and volunteering is beyond the scope of this review, it is important to stress that many of the associations established in our meta-analysis fit into existing theoretical approaches to volunteering. For instance, Wilson and Musick (1997) in their 'integrated theory of volunteering' suggested that volunteering is affected by three types of capital or resources that individuals may have available: human, social and cultural resources. Many of the individual factors that were found to be associated with volunteering in our review can be clearly linked to these three types of resources. Factors like income, educational attainment and functional limitations can be viewed as indicators of the amount of human resources that individuals have available. Factors like marital status and network size constitute indicators of social resources. Finally, a factor like religiosity can be viewed as an indicator of cultural capital or resources that predispose individuals to volunteering. 

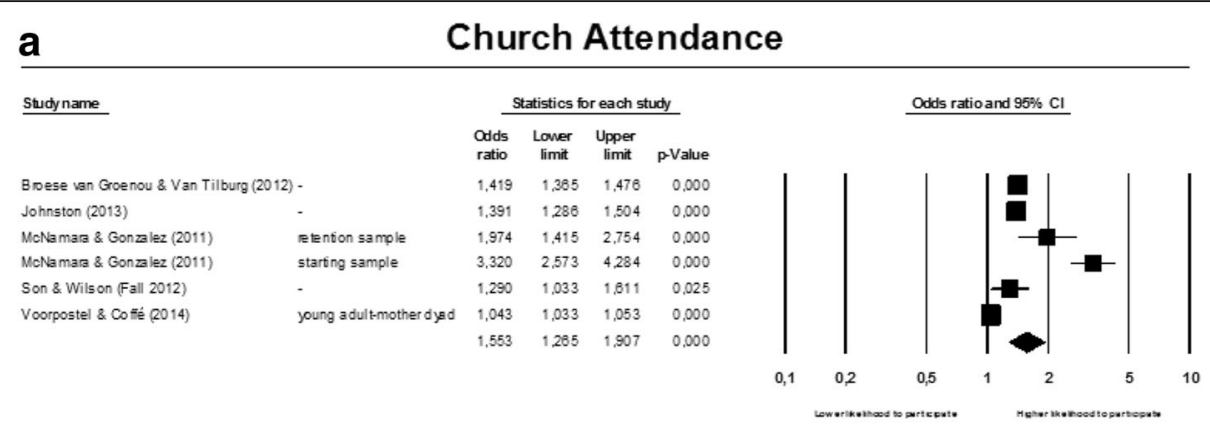

Heterogeneity: $Q=360.1, d f=5, p=0.000,1 \wedge 2=99 \%$

b Religious Identification

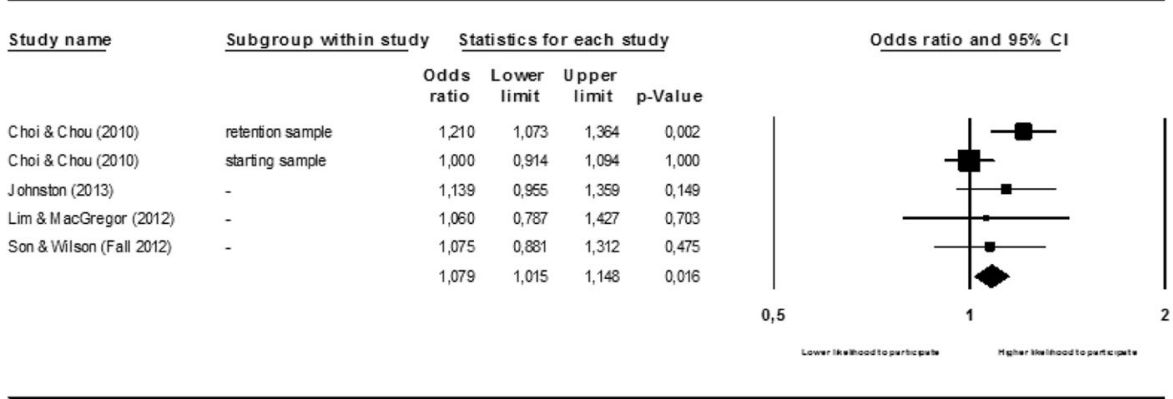

Heterogeneity: $Q=6.6, d f=4, p=0.158, \mid \wedge 2=39 \%$

Fig. 7 Forest plots for religion

\section{Strengths and limitations}

This review was conducted according to the latest standards for conducting systematic reviews and meta-analyses. This is the first review for which findings can be generalized to the general adult population in developed countries and for which associations between identified factors and participation in voluntary work were quantified by conducting meta-analyses. We transformed all estimates into ORs in order to compare the results of included studies. A thorough overview of all determinants of volunteering studied in recent publications is provided (i.e. demographic determinants, as well as determinants related to socioeconomic status, participation in other productive activities, health status, religion and social relationships), instead of focusing on a single determinant only (e.g. health status or socioeconomic status). Updating the current state of knowledge on factors related to volunteering was important, as the research on volunteering has taken a giant leap recently. Results from our search strategy showed that compared to a decade ago, publications on factors related to volunteering have more than doubled (our search resulted in 1620 hits for the period 2000-2005 compared to 3774 hits for the period 2010-2015).

Some limitations must be mentioned as well. We limited the inclusion of studies to those published in the period 2010-2015. The choice for including this quite narrow time period was made for two main reasons. Firstly, because participation in voluntary work is related not only to individual characteristics but also to macro factors such as the demographic composition of populations, economic circumstances and government regimes, we argue that taking into account the most recent time period is the most relevant period to study in order to increase our knowledge on contemporary determinants of volunteering and provide insight in the characteristics of potential volunteers nowadays. Secondly, in trying to find a good balance between recency and efficiency, we chose to develop a rather broad search strategy without specifying any determinants beforehand, in order to provide the most comprehensive overview of all determinants studied in relation to volunteering. We cannot be sure whether our results would have been different if all studies irrespective of the date of publication were to be included. Probably the results for the factors studied in this review would be more heterogeneous due to cohort effects and probably some additional factors studied in earlier publications may have been identified. Moreover, although the studies included in this review were all published recently, the vast majority (79\%) of the included studies used data with baseline measurements before the year 2005. Potentially, the results would have been different if we would have limited the inclusion of studies to those using recent data. Our search was 
conducted in August 2015 and several relevant articles have been published afterwards [42-46]. The results of this articles are in line with the results included in this systematic review and meta-analysis, showing for example that individuals in worse mental health are less likely to participate in voluntary work [42], religiosity in adulthood is positively associated to volunteering [43], and that previous volunteer experiences, good health and higher education are positively associated to volunteering [44]. Moreover, two studies investigated the association between providing care to grandchildren and volunteering $[45,46]$ but with opposite results. Therefore, it seems unlikely that including studies published after August 2015 would alter the conclusions drawn in the current study. Moreover, the inclusion of studies was limited to studies written in English, Dutch, French or German. The inclusion of only English, Dutch, French and German language studies may have led to missing some studies, however there is little evidence that exclusion of non-English-language studies leads to systematic bias in systematic reviews [47-50].

Visual inspection of the forest plots and Egger's test have shown the presence of funnel plot asymmetry for the studies investigating the factors age and marital status in relation to the likelihood to volunteer. Therefore, these results should be interpreted with caution, as the reported effect sizes might be an overestimation of the true effect due to publication bias. However, using Egger's approach could lead to false-positive results in the case of dichotomous outcomes [10]. However, we do not consider publication bias to be very likely. The majority of the included studies took age and marital status into account as control variables and their main interest was often directed towards the association between other factors and volunteering. Therefore, we do not expect publication bias to be a substantial problem for the results presented in this review. Funnel plot asymmetry can be caused not only by publication bias, but low methodological quality could also lead to the inflation of effects in smaller studies [10]. The latter could play a role. The majority of the studies included in this review did not provide information on the characteristics of respondents compared to participants lost to follow-up and differences between these groups could have contributed to funnel plot asymmetry.

\section{Recommendations for further research}

The studies included in this review were very heterogeneous in terms of the methodological quality and study population. Results were also heterogeneous and, unfortunately, heterogeneity could often not be properly explained. The risk of bias assessment of the included studies has pointed out the presence of reporting flaws in included studies. Although attrition was in general high in the included studies, the majority of the studies (79.2\%) did not report information regarding potential differences between participants and drop-outs, therefore insufficient information is available to assess the likelihood of attrition bias in included studies. Moreover, more than half of the studies (54.2\%) did not report information on the participation rate at baseline. These are important reporting flaws, because selectivity in the study sample could have a major influence on the findings. Finally, half of the studies (50.0\%) did not report information on how missing data was dealt with. For correct interpretation of the findings, it is important to know whether and how data has been imputed. In future research, more attention should be directed towards the quality of reporting as recommended in the STROBE guidelines (39).

The focus of the current systematic review and meta-analysis was to investigate the individual determinants of volunteering. Other determinants play a role as well in predicting volunteering. Contextual factors, for example, are important determinants of volunteering too [51]. Anheier \& Salomon [52] (page 43) described that volunteering is determined by the way how societies are organized, how they allocate social responsibilities, and how much engagement and participation they expect from citizens. The heterogeneity between the results of the included studies could also be attributable to contextual differences between countries or cultures. Therefore, in future cross-national research on individual determinants of volunteering, it would be interesting to take into account cultural and country specific aspects. Moreover, our review showed that most studies are concentrated in the USA and selected European countries. It would be important for future research to diversify studies in terms of geographical spread. Our review has provided evidence for the association between several factors (e.g. socioeconomic status, marital status, parental status, functional health, previous volunteering, social network size and religion) and participation in voluntary work. In future research on determinants of participation in voluntary work, these factors should thus be taken into account as potential confounders in the analyses. This review has identified several gaps in the literature as well. Firstly, (weak) evidence was found for the negative association between age and volunteering from middle-age onwards. Studies including adults below middle-age were substantially underrepresented in this review. Therefore, more research should be done to examine the determinants of participation in voluntary work among younger adults and more specific, on the association between age and volunteering in younger age groups.

Secondly, more research is needed on the association between socioeconomic status and volunteering. Socioeconomic status seems to be related to the likelihood to volunteer; weak evidence for the association 
between education and volunteering was found and, although the overall result for the association between income and volunteering was inconclusive, for specific groups of individuals (aged 55 and over and those living in the USA) we did find a positive association. Another related factor is employment status. We did not find an association between employment status and volunteering but the pooled estimate was boundary significant and indicates the presence of a possible negative association between employment status and the likelihood to volunteer. Studies assessing the association of participation in voluntary work with employment status, level of income and education were very heterogeneous with respect to the confounders they took into account. Further research should investigate the association between these factors and participation in voluntary work, taking both educational attainment, employment status and income level into account as not only these factors themselves but also the interplay between these factors may be important in predicting participation in voluntary work.

Thirdly, this review has shown the importance of two types of life course transitions in predicting the likelihood to volunteer. For both increases in the degree to which an individual is functionally limited as well as the recent birth of a child in the household, a strong negative association with participation in voluntary work was found. Regarding parenthood, the recent birth of a child is negatively associated to volunteering whereas the presence of children in the household in general seems to be positively associated to volunteering, which shows the importance of disentangling these factors. Despite the evident importance of life course transitions in predicting the likelihood to volunteer, the majority of studies included in this review did not take them into account. In future research, the effect of major life course transition with respect to family life (for example changes in household composition, partnership status and health of family members), work (for example starting a career after graduation, transitions into and out of unemployment, changes in working hours and retirement) and health should be taken into account.

New research in the field of volunteering should aim at filling the gaps mentioned above, because volunteering is an increasingly important activity for developed societies facing aging populations. Therefore, it is important to know for policy makers which characteristics are related to volunteering in order to identify potential volunteers.

\section{Conclusions}

In the current study, important key factors have been identified. The results of this study show that socioeconomic status, being married, social network size, church attendance and previous volunteer experiences are positively associated with volunteering and that age, functional limitations and transitions into parenthood were found to be inversely related to volunteering. A need exists for studies directed towards deepening the knowledge on the associations several between the factors and participation in voluntary work, among which are age, education, income and employment. Moreover, major life course transitions should be studied in relation to volunteering.

\section{Appendix 1}

\section{Search strings MEDLINE, PsychINFO, SocINDEX, Business Source Premier and EconLit MEDLINE}

("Volunteers"[MeSH:NoExp] OR "Hospital Volunteers" [MeSH].

OR

"volunteering"[tiab] OR "volunteerism"[tiab] OR "voluntary worker"[tiab] OR "voluntary workers"[tiab] OR "voluntary work"[tiab] OR "voluntary association"[tiab] OR "voluntary associations"[tiab] OR "voluntary activities"[tiab] OR "lay worker"[tiab] OR "lay workers"[tiab] OR "unpaid work"[tiab])

\section{AND}

("Age Factors"[MeSH] OR "Aspirations(psychology)"[$\mathrm{MeSH}]$ OR "Attitude"[MeSH:NoExp] OR "Behavior" [MeSH:NoExp] OR "Causality"[MeSH:NoExp] OR "Comorbidity" $[\mathrm{MeSH}] \mathrm{OR}$ "Goals" [MeSH] OR "Helping Behavior" $[\mathrm{MeSH}]$ OR "Intention"[MeSH] OR "Motivation"[MeSH:NoExp] OR "Psychology"[MeSH] OR "Reward"[MeSH] OR "Self Efficacy"[MeSH] OR "Sex Factors"[MeSH] OR "Sociological Factors"[MeSH].

OR

"barrier"[tiab] OR "barriers"[tiab] OR "choice"[tiab] OR "choices"[tiab]OR "characteristic"[tiab] OR "characteristic$\mathrm{s}$ "[tiab] OR "determinant"[tiab] OR "determinants"[tiab] OR "factor" [tiab] OR "factors"[tiab] OR "goal"[tiab] OR "goals"[tiab] OR "incentive" [tiab] OR "incentives"[tiab] OR "likely"[tiab] OR "likelihood"[tiab] OR "motivation"[tiab] OR "motivations" [tiab] OR "motive"[tiab] OR "motive$\mathrm{s}$ "[tiab] OR "predict"[tiab] OR "predicts"[tiab] OR "prediction"[tiab] OR "predictor"[tiab] OR "predictors"[tiab] OR "reason"[tiab] OR "reasons"[tiab] OR "relation"[tiab] OR "relations"[tiab] OR "relationship"[tiab] OR "why"[tiab] OR "willingness" [tiab]).

\section{PsychINFO}

(DE "Volunteers".

OR

TI (volunteering OR volunteerism OR "voluntary work" "OR "volunteer work" OR "voluntary association" OR "unpaid work"*).

OR 
$\mathrm{AB}$ (volunteering $\mathrm{OR}$ volunteerism OR "voluntary work" OR "volunteer work" " OR "voluntary association" OR "lay work" OR "unpaid work"))

AND

(DE "Academic Achievement Motivation" OR DE "Achievement Motivation" OR DE "Altruism" OR DE “Aspirations” OR DE “Attitudes” OR DE “Attribution” OR DE "Causal Analysis" OR DE "Commitment" OR DE "Employee Motivation" OR DE "Extrinsic Motivation” OR DE "Goals" OR DE "Human Capital" OR DE "Incentives" OR DE "Intention" OR DE "Intrinsic Motivation" OR DE "Motivation" OR DE "Needs" OR DE "Occupational Aspirations" OR DE "Organizational Commitment" OR DE "Planned Behavior" OR DE "Prediction" OR DE "Prosocial Behavior" OR DE "Reasoned Action" OR DE "Rewards" OR DE "Self Expansion" OR DE "Social Capital” OR DE "Social Behavior" OR DE "Social Perception".

OR

TI (barrier OR barriers OR choice OR choices OR characteristic OR characteristics OR determinant OR determinants $\mathrm{OR}$ factor OR factors OR goal OR goals OR incentive OR incentives OR likely OR likelihood OR motivation OR motivations OR motive OR motives OR predict OR prediction OR predictor OR predictors $\mathrm{OR}$ reason $\mathrm{OR}$ reasons $\mathrm{OR}$ relation $\mathrm{OR}$ relations $\mathrm{OR}$ relationship $\mathrm{OR}$ relationships $\mathrm{OR}$ why OR willingness).

OR

AB (barrier OR barriers OR choice OR choices OR characteristic OR characteristics OR determinant OR determinants OR factor OR factors OR goal OR goals OR incentive OR incentives OR likely OR likelihood OR motivation OR motivations OR motive OR motives OR predict $\mathrm{OR}$ prediction $\mathrm{OR}$ predictor OR predictors OR reason $\mathrm{OR}$ reasons $\mathrm{OR}$ relation $\mathrm{OR}$ relations $\mathrm{OR}$ relationship OR relationships OR why OR willingness)).

\section{SocINDEX}

(DE “LAY Ministry” OR DE “VOLUNTEERS” OR DE "STUDENT volunteers in social services" OR DE "VOLUNTEER workers in social services" OR DE "VOLUNTEER service" OR DE "WOMEN volunteers in social services" OR DE "YOUNG volunteers in social services" OR DE “OLDER volunteers in social services".

OR

TI (volunteering OR volunteerism OR "voluntary work" OR "volunteer work" *" OR "voluntary association"” OR "unpaid work").

OR

$\mathrm{AB}$ (volunteering OR volunteerism OR "voluntary work" OR "volunteer work" OR "voluntary association" OR "lay work" OR "unpaid work"))

AND

(DE “ASSOCIATIONS, institutions, etc.” OR DE “ATTITUDE (psychology)” OR DE "BEHAVIORISM (psychology)”
OR DE "BEHAVIOR" OR DE "HUMAN behavior" OR DE "PROSOCIAL behavior" OR DE "HELPING behavior" OR DE "PLANNED behavior theory" OR DE "MOTIVATION (psychology)" OR DE "EMPLOYEE motivation" OR DE "GOAL (psychology)" OR DE "REWARD (psychology)" OR DE "SELF-actualization (psychology)" OR DE "SELFdetermination theory" OR DE "SOCIOEMOTIONAL selectivity theory" OR DE "COMMITMENT" OR DE "PSYCHOLOGY" OR DE "INFLUENCE (Psychology)" OR DE "HUMAN capital” OR DE "SOCIAL capital (Sociology)” OR DE “CULTURAL capital”.

OR

TI (barrier OR barriers OR choice OR choices OR characteristic OR characteristics OR determinant OR determinants OR factor OR factors OR goal OR goals OR incentive OR incentives OR likely OR likelihood OR motivation OR motivations OR motive OR motives OR predict $\mathrm{OR}$ prediction $\mathrm{OR}$ predictor OR predictors OR reason $\mathrm{OR}$ reasons $\mathrm{OR}$ relation $\mathrm{OR}$ relations $\mathrm{OR}$ relationship OR relationships OR why OR willingness).

OR

AB (barrier OR barriers OR choice OR choices OR characteristic OR characteristics OR determinant OR determinants OR factor OR factors OR goal OR goals OR incentive OR incentives OR likely OR likelihood OR motivation OR motivations OR motive OR motives OR predict $\mathrm{OR}$ prediction $\mathrm{OR}$ predictor $\mathrm{OR}$ predictors $\mathrm{OR}$ reason $O R$ reasons $O R$ relation $O R$ relations $O R$ relationship OR relationships OR why OR willingness).

\section{Business Source Premier}

DE "STUDENT volunteers in social services" OR DE "VOLUNTEERS" OR DE "VOLUNTEERS -- psychology" OR DE "VOLUNTEER recruitment" OR DE "VOLUNTEER service" OR DE "VOLUNTEER workers in income tax return preparation" OR DE "VOLUNTEER workers in social services" OR DE "WOMEN volunteers in social services" OR DE "YOUNG volunteers in social services".

OR

TI (volunteering OR volunteerism OR "voluntary work" OR "unpaid work").

OR

$\mathrm{AB}$ (volunteering $\mathrm{OR}$ volunteerism OR "voluntary work" OR "volunteer work" OR "voluntary association"” OR "lay work" OR "unpaid work"*")

\section{AND}

DE “ATTITUDE (psychology)" OR DE "BEHAVIOR” OR DE "BEHAVIORAL research" OR DE "CONSUMER behavior" OR DE "DECISION making” OR DE "DISCRIMINATION in employment" OR DE "GENDER role in the work environment" OR DE "HUMAN behavior" OR DE "INCENTIVES in industry" OR DE "PROSOCIAL behavior" OR DE "HELPING behavior" OR DE "PLANNED behavior theory" OR DE "MOTIVATION 
(psychology)" OR DE "EMPLOYEE motivation" OR DE "REWARD (psychology)" OR DE "SELF-actualization (psychology)" OR DE "SELF-determination theory" OR DE "COMMITMENT" OR DE "HUMAN capital" OR DE "SOCIAL capital" OR DE "CULTURAL capital".

OR

TI (barrier OR barriers OR choice OR choices OR characteristic OR characteristics OR determinant OR determinants OR factor OR factors OR goal OR goals OR incentive OR incentives OR likely OR likelihood OR motivation OR motivations OR motive OR motives OR predict $\mathrm{OR}$ prediction $\mathrm{OR}$ predictor $\mathrm{OR}$ predictors $\mathrm{OR}$ reason OR reasons OR relation OR relations OR relationship OR relationships OR why OR willingness).

OR

$A B$ (barrier OR barriers OR choice OR choices OR characteristic OR characteristics OR determinant OR determinants OR factor OR factors OR goal OR goals OR incentive OR incentives OR likely OR likelihood OR motivation OR motivations OR motive OR motives OR predict OR prediction OR predictor OR predictors OR reason OR reasons OR relation OR relations OR relationship OR relationships OR why OR willingness).

\section{EconLit}

TI (volunteer OR volunteers OR volunteering OR volunteerism OR "voluntary work" OR "volunteer work" OR "voluntary association"”).

\section{OR}

$\mathrm{AB}$ (volunteer OR volunteers OR volunteering OR volunteerism OR "voluntary work" OR "volunteer work" OR "voluntary association"”)

\section{AND}

TI (attitude OR attitudes OR barrier OR barriers OR behavior OR choice OR choices OR characteristic OR characteristics OR commitment OR "cultural capital" OR determinant OR determinants OR factor OR factors OR goal OR goals OR "human capital" OR incentive OR incentives OR likely OR likelihood OR motivation OR motivations OR motive OR motives OR predict OR prediction OR predictor OR predictors OR reason OR reasons $\mathrm{OR}$ relation $\mathrm{OR}$ relations $\mathrm{OR}$ rewards $\mathrm{OR}$ relationship OR relationships OR "social capital" OR why OR willingness).

OR

$A B$ (attitude OR attitudes OR barrier OR barriers OR behavior OR choice OR choices OR characteristic OR characteristics OR commitment OR "cultural capital" OR determinant OR determinants OR factor OR factors OR goal OR goals OR "human capital" OR incentive OR incentives OR likely OR likelihood OR motivation OR motivations OR motive OR motives OR predict OR prediction OR predictor OR predictors $\mathrm{OR}$ reason $\mathrm{OR}$ reasons $\mathrm{OR}$ relation $\mathrm{OR}$ relations OR rewards OR relationship OR relationships OR "social capital" OR why OR willingness)

\section{Appendix 2}

Table 7 Risk of Bias assessment tool (based on QUIPS, Hayden et al. [13])

\begin{tabular}{|c|c|}
\hline Domain & Items \\
\hline $\begin{array}{l}\text { 1. Study } \\
\text { participation }\end{array}$ & $\begin{array}{l}\text { 1a. Method used to identify population: } \\
\text { recruitment of participants for the study was } \\
\text { performed in a consecutive way } \\
\text { 1b. Adequate study participation: at least } 70 \% \\
\text { of recruited individuals agreed to participate }\end{array}$ \\
\hline 2. Study attrition & $\begin{array}{l}\text { 2a. Adequate follow-up rate: at least } 80 \% \text { of the } \\
\text { baseline study participants participated at } \\
\text { follow-up } \\
\text { 2b. There are no important differences between } \\
\text { participants who completed the study and } \\
\text { those who did not }\end{array}$ \\
\hline $\begin{array}{l}\text { 3. Determinant } \\
\text { measurement }\end{array}$ & $\begin{array}{l}\text { 3a. Adequate proportion of complete data: } \\
\text { at least } 70 \% \text { of the study sample has } \\
\text { complete data on the determinant(s) } \\
\text { 3b. The method and setting of determinant } \\
\text { measurement is the same for all study } \\
\text { participants } \\
\text { 3c. Appropriate methods of imputation are } \\
\text { used for missing determinant data }\end{array}$ \\
\hline $\begin{array}{l}\text { 4. Outcome } \\
\text { measurement }\end{array}$ & $\begin{array}{l}\text { 4a. Outcome measure truly captures } \\
\text { participation in voluntary work and does } \\
\text { not allow for participation in informal } \\
\text { caregiving or other productive activities } \\
\text { not equal to volunteering, unless } \\
\text { subgroups are made for the distinct } \\
\text { forms of participation } \\
\text { 4b. The method and setting of outcome } \\
\text { measurement is the same for all study } \\
\text { participants }\end{array}$ \\
\hline $\begin{array}{l}\text { 5. Study } \\
\text { confounding }\end{array}$ & $\begin{array}{l}\text { 5a. The following potentially important } \\
\text { confounders are measured: } \\
\text { a1. age } \\
\text { a2. socioeconomic status (e.g. education, income) } \\
\text { a3. gender } \\
\text { a4. participation in voluntary work at baseline } \\
\text { 5b. The method and setting of measurement of } \\
\text { the confounders is the same for all study } \\
\text { participants } \\
\text { 5c. Appropriate methods of imputation are used } \\
\text { for missing data regarding the confounders } \\
\text { 5d. The following potentially important confounders } \\
\text { are accounted for in the study design (e.g., } \\
\text { matching for key variables, stratification, or initial } \\
\text { assembly of comparable groups) or in the analysis } \\
\text { (i.e., appropriate adjustment) } \\
\text { d1. age } \\
\text { d2. socioeconomic status (e.g. education, income) } \\
\text { d3. gender } \\
\text { d4. participation in voluntary work at baseline }\end{array}$ \\
\hline $\begin{array}{l}\text { 6. Statistical } \\
\text { analysis and } \\
\text { reporting }\end{array}$ & $\begin{array}{l}\text { 6a. The selected statistical model is adequate for } \\
\text { the design of the study design } \\
\text { 6b. There is no over fitting (at least } 10 \text { participants } \\
\text { in the smallest group per determinant and } \\
\text { outcome variable) } \\
\text { 6c. There is no selective reporting of results }\end{array}$ \\
\hline
\end{tabular}




\section{Appendix 3}

Table $\mathbf{8}$ Determinants measured in included studies

\begin{tabular}{ll}
\hline Author & Determinants $^{\text {a }}$ \\
\hline Ajrouch et al. [18] & $\begin{array}{l}\text { Social network (size, proportion of family, age, proximity, frequency), education, age, gender, race, health } \\
\text { limitation and depression }\end{array}$ \\
Bartels et al. [19] & $\begin{array}{l}\text { Ratio government expenditure / GDP, interest in politics, children, education, marital status, income, liking } \\
\text { the neighbourhood }\end{array}$ \\
Bekkers [20] & Trust
\end{tabular}

Broese van Groenou \& Van Tilburg [21] Age, gender, cohort, education, employment status, health status, marital status, size of personal network and church attendance

Choi \& Chou [22]

Education, income, health, work status, religion, generative qualities, number of meetings attended, age, marital status, ethnicity and gender

Cramm \& Nieboer [23]

Age, gender, ethnicity, marital status, education, social capital, social functioning, cognitive functioning and physical functioning, volunteering at baseline

Curl et al. [24]

Driving status, waves since driving cessation, gender, age, ethnicity, education, marital status, household income, depressive symptoms, chronic conditions, self-rated health, IADL limitations and cognitive ability

Curl et al. [25]

Einolf \& Philbrick [26]

For both the individual and the spouse: driving status, waves since driving cessation, age, ethnicity, education, couple income, cognitive ability, chronic conditions, IADL limitations and self-rated health

Marriage (covariates taken into account but no effect size provided are: volunteering at baseline, ethnicity, education, age, health, hours worked, religious attendance, housework hours and children

Hank \& Erlinghagen [27]

Gender, age, education, partnership status, employment status, self-rated health, country

Johnston [28]

Religious importance, religious attendance, family income, functional health, employment status, child currently at home, marital status

Lim \& Mac Gregor [29]

Age, gender, ethnicity, income, education, marriage, children, social involvement index, voluntary group involvement, religious tradition, religious index, region, volunteering at baseline, number of close friends, ethnicity of friends, religiosity of friends

McNamara \& Gonzales [30]

Age, ethnicity, gender, volunteering at baseline, assets, education, income, health, marital status, volunteer status of spouse, like to spend time with spouse, spousal caregiving, parental caregiving, children, employment status, provision of informal help in community, religious attendance

Mike et al. [31]

Age, gender, education, personality traits: conscientiousness, extraversion, agreeableness, neuroticism and openness, current work status

Nesbit [32]

Volunteering at baseline, gender, age, ethnicity, education, birth of child, divorce, death in family

Okun et al. [33]

Volunteer satisfaction and enjoyment, age, gender, race, hours worked p/wk., education, functional limitations, social interaction, attending clubs /organizations and church attendance

Parkinson [34]

Area of residence, country of birth, English proficiency, education, health care insurance, living arrangements, transport, SF36, DSSI, number of visits to healthcare professionals

Pavlova \& Silbereisen [35]

Coping strategies for occupational uncertainty, region, community size, gender, education, income, employment status, partnership status and general health

Pavlova \& Silbereisen [36]

Perceived activation demands, volunteering at baseline, age and self-rated health

Son \& Wilson [37]

Generativity,religious identification, church attendance, spirituality, religious coping, parental religion, parental sociability, education, age, gender, ethnicity, marital status and income

Son \& Wilson [38]

Altruistic obligation, civic obligation, religious identification, spirituality, religious coping, public religiosity, parental religion, education, age, gender, ethnicity, marital status, income, employment, physical health, religious tradition, contact frequency with friends

Son \& Wilson [39]

Hedonic well-being, eudemonic well-being, social well-being, age, gender, ethnicity, marital status, education, income, employment, church attendance, physical health

Voorpostel \& Coffé [40]

Transitions in partnership, transitions in parental status, age, (change in) education, (change in) employment status, volunteering at baseline

Voorpostel \& Coffé [41]

Parental separation, parental levels of voting and volunteering, parental occupation and education, young adults living situation, age, gender, schooling, education, occupation and church visits

${ }^{a}$ The determinants listed here are only those determinants for which the association with the outcome is measured longitudinally and are therefore eligible for inclusion in the meta-analysis 


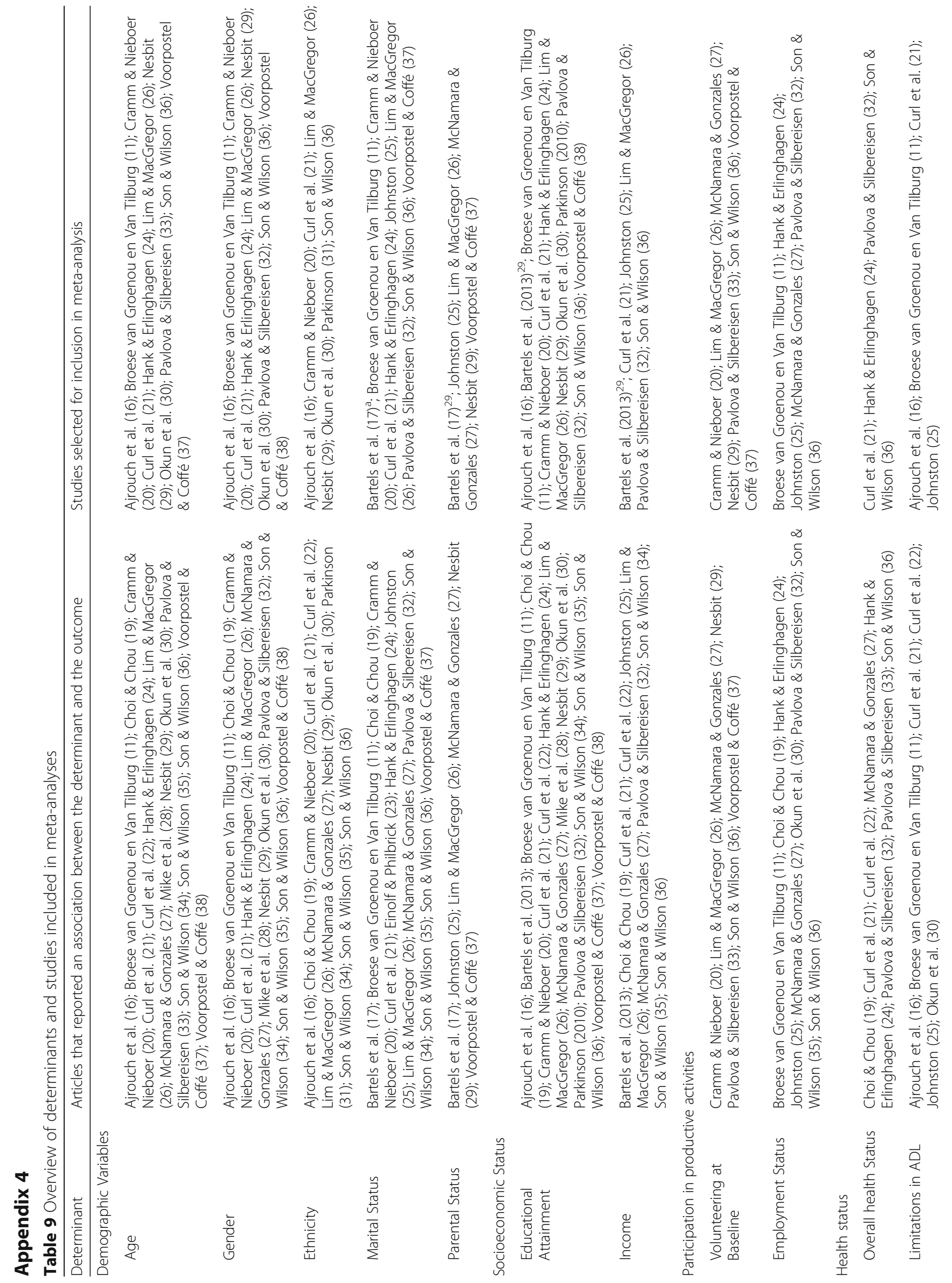


Niebuur et al. BMC Public Health $\quad$ (2018) 18:1213

Page 28 of 30

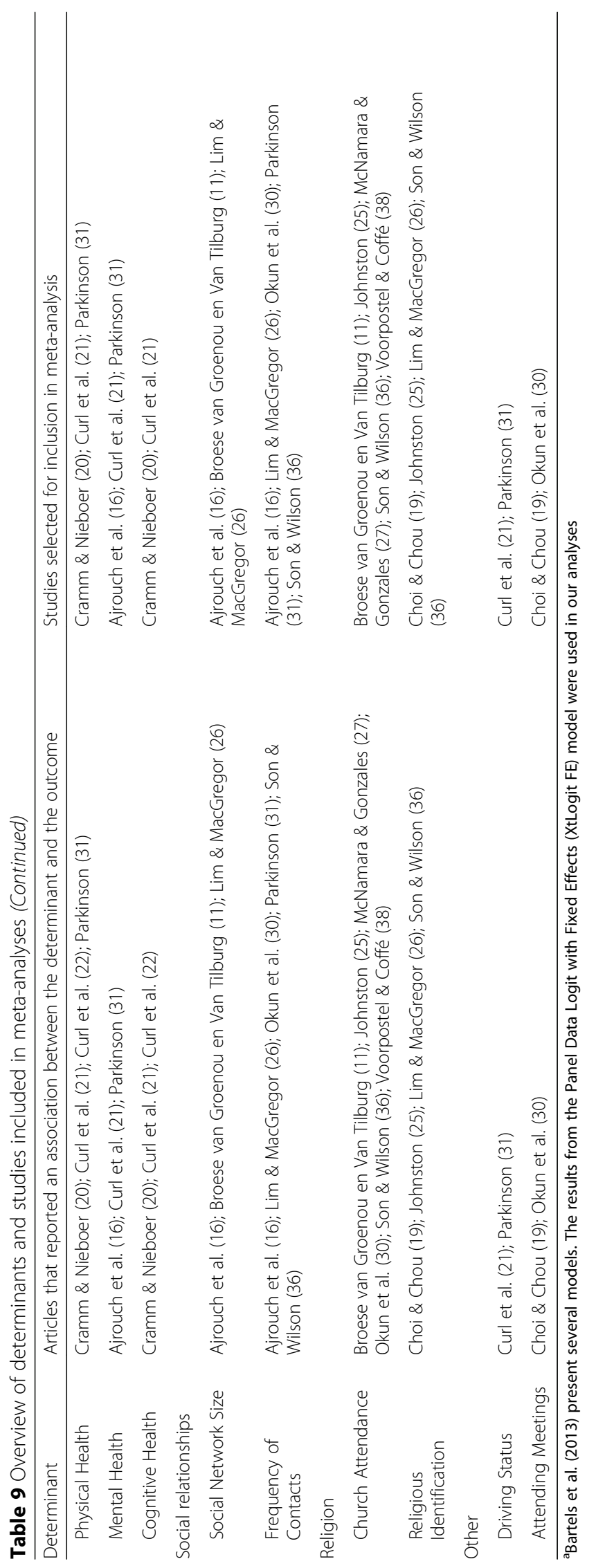




\section{Abbreviations}

Cls: Confidence Intervals; ORs: Odds Ratios; PRISMA: Preferred Reporting Items for Systematic Reviews and Meta-Analyses; QUIPS: Quality In Prognosis Studies; USA: United States of America

\section{Acknowledgements}

We would like to thank Sjoukje van der Werf (University of Groningen, University Medical Center Groningen) for her assistance with the search strategy for the databases. We would also like to thank dr. Koen Bartels (Bangor University), professor René Bekkers (VU Amsterdam), Angela Curl, Ph.D. (Miami University), dr. Noemi Mantovan (Bangor University), Rebecca Nesbit, Ph.D. (The University of Georgia), dr. Maria Pavlova (Friedrich Schiller University of Jena), dr. Marieke Voorpostel (FORS, Switzerland) and Professor John Wilson (Duke University) for providing us the additional information on the models or additional data of their studies needed to calculate odds ratios.

\section{Funding}

This study was funded by a crowd funding campaign performed by the Ubbo Emmius Fonds Groningen, which transferred the proceeds as a gift to the University of Groningen. The funders had no role in study design, data collection, analysis and interpretation and writing the manuscript.

\section{Availability of data and materials}

The datasets used and analyzed during the current study are available from the corresponding author on reasonable request.

\section{Authors' contributions}

All authors were involved in the conception and design of this study. JN and LVL conducted the search, screened all abstracts and full-text papers for eligibility and performed quality assessment and data-extraction. JN wrote the drafts of the manuscript and all other authors critically revised the different versions of the manuscript. Moreover, all authors were involved in discussing the results and interpreting the findings. All authors read and approved the final manuscript.

\section{Ethics approval and consent to participate}

Not applicable.

\section{Consent for publication}

Not applicable.

\section{Competing interests}

The authors declare that they have no competing interests.

\section{Publisher's Note}

Springer Nature remains neutral with regard to jurisdictional claims in published maps and institutional affiliations.

\section{Author details}

'Department of Epidemiology, University of Groningen, University Medical Center Groningen, Hanzeplein 1, PO Box 30 001, FA40, 9700, RB, Groningen, The Netherlands. ${ }^{2}$ Netherlands Interdisciplinary Demographic Institute, The Hague, the Netherlands. ${ }^{3}$ Department of Sociology, Vrije Universiteit Amsterdam, Amsterdam, the Netherlands. ${ }^{4}$ Department of Sociology, University of Groningen, Groningen, the Netherlands. ${ }^{5}$ Department of Health Psychology, University of Groningen, University Medical Center Groningen, Groningen, the Netherlands. ${ }^{6}$ Department of Geriatrics, University of Groningen, University Medical Center Groningen, Groningen, The Netherlands.

\section{Received: 30 January 2018 Accepted: 1 October 2018}

\section{Published online: 02 November 2018}

\section{References}

1. Okun MA, Yeung EW, Brown S. Volunteering by older adults and risk of mortality: a meta-analysis. Psychol Aging. 2013;28:564-77 Available from: http://doi.apa.org/getdoi.cfm?doi=10.1037/a0031519.

2. Jenkinson CE, Dickens AP, Jones K, Thompson-Coon J, Taylor RS, Rogers M et al. Is volunteering a public health intervention? A systematic review and meta-analysis of the health and survival of volunteers. BMC Public Health.
2013;13:773 Available from: http://bmcpublichealth.biomedcentral.com/ articles/10.1186/1471-2458-13-773.

3. Anderson ND, Damianakis T, Kröger E, Wagner LM, Dawson DR, Binns MA, et al. The benefits associated with volunteering among seniors: A critical review and recommendations for future research. Psychol Bull. 2014;140: 1505-33 Available from: http://doi.apa.org/getdoi.cfm?doi=10.1037/ a0037610.

4. Galenkamp H, Deeg DJH. Increasing social participation of older people: are there different barriers for those in poor health? Introduction to the special section. Eur J Ageing Springer Netherlands. 2016;13:87-90.

5. International Labour Office Geneva. Manual on the measurement of volunteer work. Geneva: International Labour Office (ILO); 2011. p. 1-120. ISBN 978-92-2-125071-5. www.lo.org/publnsl.

6. Salamon LM, Sokolowski SW, Megan A, Tice HS. The state of global civil society and volunteering: latest findings from the implementation of the UN nonprofit handbook, Work Pap John Hopkins Comp Nonprofit Sect Proj, vol. 49; 2013. p. 18.

7. Godbout E, Filiatrault J, Plante M. La participation des aînés à des activités de bénévolat: Une revue systématique. Can J Occup Ther [Internet]. 2012; 79:23-32 Available from: http://cjo.sagepub.com/lookup/doi/10.2182/cjot. 2012.79.1.4

8. Hallett C, Klug LC. Volunteering in the care of people with severe mental illness: a systematic review. BMC Psychiatry. 2012;12.

9. Wilson J. Volunteering. Ann Rev Sociol. 2000;26:215-40.

10. Higgins JP Green S. Cochrane handbook for systematic reviews of interventions. 2011.

11. Moher D, Liberati A, Tetzlaff J, Altman DG. Academia and clinic annals of internal medicine preferred reporting items for systematic reviews and meta-analyses: the PRISMA statement. Annu Intern Med. 2009;151: 264-9.

12. Wilson J, Musick M. Who Cares? Toward an Integrated Theory of Volunteer Work. Am Sociol Rev. 1997;62(5):694-713.

13. Hayden JA, Van Der Windt DA, Cartwright JL, Côté P. Research and reporting methods annals of internal medicine assessing Bias in studies of prognostic factors. Ann Intern Med. 2013;144:427-37.

14. Altman DG. Practical statistics for medical research. London: Chapman and Hall; 1991

15. Kuiper JS, Zuidersma M, Zuidema SU, Burgerhof JGM, Stolk RP, Oude Voshaar RC, et al. Social relationships and cognitive decline: a systematic review and meta-analysis of longitudinal cohort studies. Int J Epidemiol. 2016; dyw089. Available from: https://academic.oup.com/ije/article-lookup/ doi/10.1093/ije/dyw089.

16. Higgins JPT, Thompson SG, Deeks JJ, Altman DG. Measuring inconsistency in meta-analyses. BMJ Br Med J. 2003;327:557-60.

17. Stuck AE, Rubenstein LZ, Wieland D, Vandenbroucke JP, Irwig L, Macaskill P, et al. Bias in meta-analysis detected by a simple, graphical. Bmj. 1998;316: 469-469. Available from: http://www.bmj.com/cgi/doi/10.1136/bmj.316. 7129.469

18. Ajrouch KJ, Antonucci TC, Webster NJ. Volunteerism: social network dynamics and education. J Gerontol B Psychol Sci Soc Sci. 2016;71:309-19.

19. Bartels KP, Cozzi G, Mantovan N. "The Big Society," Public Expenditure, and Volunteering. Public Adm Rev. 2013;73(2);340-51.

20. Bekkers R. Trust and volunteering: selection or causation? Evidence from a 4 year panel study. Polit Behav. 2012;34:225-47.

21. Broese Van Groenou M, Van Tilburg T. Six-year follow-up on volunteering in later life: a cohort comparison in the Netherlands. Eur Sociol Rev. 2012;28:1-11.

22. Choi NG, Chou RJ-A. Time and money volunteering among older adults: the relationship between past and current volunteering and correlates of change and stability. Ageing Soc. 2010;30:559-81 Available from: http:// www.journals.cambridge.org/abstract_S0144686X0999064X.

23. Cramm JM, Nieboer AP. Background characteristics, resources and volunteering among older adults (aged $\geq 70$ years) in the community: a longitudinal study. Geriatr Gerontol Int. 2015;15:1087-95.

24. Curl AL, Stowe JD, Cooney TM, Proulx CM. Giving up the keys: how driving cessation affects engagement in later life. Gerontologist. 2014:54:423-33.

25. Curl AL, Proulx CM, Stowe JD, Cooney TM. Productive and social engagement following driving cessation. Res Aging. 2015;37:171-99 Available from: http://journals.sagepub.com/doi/10.1177/0164027514527624.

26. Einolf CJ, Philbrick D. Generous or greedy marriage? A longitudinal study of volunteering and charitable giving. J Marriage Fam. 2014;76:573-86. 
27. Hank K, Erlinghagen M. Dynamics of volunteering in older Europeans. Gerontologist. 2010;50:170-8.

28. Johnston JB. Religion and volunteering over the adult life course. J Sci Study Relig. 2013;52:733-52.

29. Lim C, MacGregor CA. Religion and volunteering in context. Am Sociol Rev. 2012;77:747-79 Available from: http://journals.sagepub.com/doi/10.1177/ 0003122412457875.

30. McNamara TK, Gonzales E. Volunteer transitions among older adults: the role of human, social, and cultural capital in later life. J Gerontol B Psychol Sci Soc Sci. 2011;66 B:490-501.

31. Mike A, Jackson JJ, Oltmanns TF. The conscientious retiree: The relationship between conscientiousness, retirement, and volunteering. J Res Pers. 2014;52. 68-77. https://doi.org/10.1016/j.jp.2014.07.002 Elsevier Inc. Available from:.

32. Nesbit R. The influence of major life cycle events on volunteering. Nonprofit Volunt Sect Q. 2012;41:1153-74 Available from: http://journals.sagepub.com/ doi/10.1177/0899764011429181.

33. Okun M, Infurna FJ, Hutchinson I. Are volunteer satisfaction and enjoyment related to cessation of volunteering by older adults? J Gerontol B Psychol Sci Soc Sci. 2016;71:439-44.

34. Parkinson L, Warburton J, Sibbritt D, Byles J. Volunteering and older women: psychosocial and health predictors of participation. Aging Ment Health. 2010;14:917-27 Available from: http://www.tandfonline.com/doi/abs/10. 1080/13607861003801045.

35. Pavlova MK, Silbereisen RK. Coping with occupational uncertainty and formal volunteering across the life span. J Vocat Behav. 2014;85:93-105. https://doi.org/10.1016/j.jvb.2014.05.005 Elsevier Inc. Available from:

36. Pavlova MK, Silbereisen RK. Perceived Expectations for Active Aging, Formal Productive Roles, and Psychological Adjustment Among the Young-Old. Res Aging. 2016;38:26-50 Available from: http://journals.sagepub.com/doi/10. $1177 / 0164027515573026$

37. Son J, Wilson J. Generativity and volunteering. Sociol Forum. 2011;26:644-67.

38. Son J, Wilson J. Volunteer work and hedonic, eudemonic, and social wellbeing. Sociol Forum. 2012;27:658-81.

39. Son J, Wilson J. Using normative theory to explain the effect of religion and education on volunteering. Sociol Perspect. 2012;55:473-99.

40. Voorpostel M, Coffé H. Transitions in partnership and parental status, gender, and political and civic participation. Eur Sociol Rev. 2012;28:28-42.

41. Voorpostel $\mathrm{M}$, Coffé $\mathrm{H}$. The effect of parental separation on young adults??? Political and civic participation. Soc Indic Res. 2014;124:295-316.

42. Andersson MA, Glanville JL. The contingent effects of mental well-being and education on volunteering. Soc Ment Health. 2016;6:90-105.

43. DeAngelis $R$, Acevedo $G$, Xu X. Secular volunteerism among Texan emerging adults: exploring pathways of childhood and adulthood religiosity. Religions. 2016;7:74.

44. Erlinghagen M. Volunteering after retirement: evidence from German panel data. Eur Soc. 2010;12:603-25.

45. Bulanda JR, Jendrek MP. Grandparenting roles and volunteer activity. J Gerontol B Psychol Sci Soc Sci. 2016;71:129-40.

46. Arpino B, Bordone V. Regular provision of grandchild care and participation in social activities. Rev Econ Househ Springer US. 2017;15:135-74.

47. Morrison A, Polisena J, Husereau D, Moulton K, Clark M, Fiander M, et al. The effect of english-language restriction on systematic review-based metaanalyses: a systematic review of empirical studies. Int J Technol Assess Health Care. 2012;28:138-44.

48. Moher D, Pham B, Lawson ML, Klassen TP. The inclusion of reports of randomised trials published in languages other than English in systematic reviews. Health Technol Assess. 2003;7(41):1-90.

49. Pham B, Klassen TP, Lawson ML, Moher D. Language of publication restrictions in systematic reviews gave different results depending on whether the intervention was conventional or complementary. J Clin Epidemiol. 2005;58:769-76.

50. Jüni P, Holenstein F, Sterne J, Bartlett C, Egger M. Direction and impact of language bias in meta-analyses of controlled trials: empirical study. Int J Epidemiol. 2002;31:115-23 Available from: https://academic.oup.com/ije/ article-lookup/doi/10.1093/ije/31.1.115.

51. Dury S, Willems J, De Witte N, De Donder L, Buffel T, Verté D. Municipality and neighborhood influences on volunteering in later life. J Appl Gerontol. 2014;35:601-26. https://doi.org/10.1177/0733464814533818.

52. Anheier HK, Salamon LM. Volunteering in cross-national perspective: initial comparisons. Law Contemp Probl. 2001;62:43. Available from: http://eprints. Ise.ac.uk/29049/1/CSWP_10_web.pdf.

Ready to submit your research? Choose BMC and benefit from:

- fast, convenient online submission

- thorough peer review by experienced researchers in your field

- rapid publication on acceptance

- support for research data, including large and complex data types

- gold Open Access which fosters wider collaboration and increased citations

- maximum visibility for your research: over $100 \mathrm{M}$ website views per year

At BMC, research is always in progress.

Learn more biomedcentral.com/submissions 